\title{
Inovação tecnológica na indústria automobilística: características e evolução recente ${ }^{1}$
}

\author{
Enéas Gonçalves de Carvalho ${ }^{2}$
}

\begin{abstract}
Resumo
O objetivo principal deste artigo é analisar as características básicas da evolução recente do processo de inovação tecnológica na indústria automobilística. A hipótese de trabalho é que estariam ocorrendo mudanças na intensidade do processo de inovação técnica nessa indústria. O ponto de partida é a observação de que, nos últimos anos, tem havido na indústria automotiva provavelmente em decorrência da intensificação da concorrência setorial e de uma maior oportunidade tecnológica - tanto uma ampliação dos gastos em P\&D quanto uma crescente incorporação da microeletrônica (nos produtos e nos processos produtivos). Finalmente, são feitas também algumas considerações procurando relacionar os resultados obtidos neste artigo com a discussão do processo de de-maturity (rejuvenescimento) industrial, proposto por Abernathy e outros autores.
\end{abstract}

Palavras-chave: Brasil - Indústria automobilística; Inovação tecnológica; Empresas multinacionais; Competitividade internacional.

\section{Abstract \\ Technological innovation in the automotive industry: features and recent evolution}

The main goal of this article is to analyze the recent evolution of the technological innovation process in the automobile industry. A provisional assumption is that could be happened changes on the auto industry technical innovation process. The starting point is the observation that, in the last years, there have been both - probably as consequence of the sectorial competition intensification and the higher technological opportunity - an amplification of the expenses in R\&D as well as an increasing incorporation of the microelectronics, in the products and in the productive processes, by the automobile industry. Finally, some considerations are made, aiming at relating the obtained results in this article with the discussion of the de-maturity industrial process proposed by Abernathy and other authors.

Key words: Brazil - Automobile industry; Technological innovation; Multinational firms, International competitiveness.

JEL F230, L620, O320.

\section{Introdução}

Nas últimas três décadas, a indústria automobilística vem passando por várias e importantes mudanças. Ainda nos anos 1970, o oligopólio automobilístico foi abalado pela emergência das montadoras japonesas no cenário internacional e

(1) Trabalho recebido em outubro de 2006 e aprovado em dezembro de 2007.

(2) Professor da Faculdade de Ciências e Letras da Universidade Estadual Paulista Júlio de Mesquita Filho (Unesp), Araraquara, SP, Brasil. E-mail: egcarva@uol.com.br. 
subseqüentemente pela introdução dos inovadores métodos de organização e de gestão da produção criados e desenvolvidos pela Toyota (Womack et al., 1990; Clark; Fujimoto, 1991; Fujimoto, 1999).

Os anos 1980 foram marcados, por um lado, pelo início do processo de difusão do sistema toyotista de produção e, por outro, pela introdução e difusão das técnicas de produção flexível. Viabilizadas pelos avanços da microeletrônica, as tecnologias de produção flexível criaram - juntamente com as inovadoras formas de organização da produção - grandes oportunidades para a introdução de inovações no setor automobilístico, tanto no processo produtivo quanto nos próprios produtos (Womack et al., 1990; Vickery, 1996; Freeman; Soete, 1997). ${ }^{3}$

Já a década de 1990 foi marcada sucessivamente pelo deslocamento do foco competitivo para o desenvolvimento de produtos e para o avanço do processo de globalização - e, também, para as conseqüências deste último processo em termos dos fatores que definem a competitividade nesse setor (Clark; Fujimoto, 1991; Sturgeon; Florida, 1999; Fujimoto; Takeishi, 2001). ${ }^{4}$ Estas últimas décadas, especialmente a partir de meados dos anos 1980, têm sido caracterizadas também por uma intensificação do processo competitivo, crescentemente global (Vickery, 1996; Fujimoto; Takeishi, 2001; DOC, 2005, 2006). Ainda que a concorrência na indústria automotiva não possa ser qualificada de dramática, ela tem sido, sem dúvida, severa (Fine et al., 1996; Fujimoto; Takeishi, 2001).

Mais recentemente, principalmente a partir de meados dos anos 1990, tem se observado também um crescente empenho das empresas automobilísticas (não só das montadoras) no desenvolvimento das chamadas tecnologias automotivas avançadas (OTP, 2003a, 2003b; NRC, 2003, 2005; DOC, 2005, 2006).

Este artigo está organizado da seguinte forma. Na seção 1, que se segue a esta introdução, procurou-se fazer, de forma breve, uma apresentação das características básicas da tecnologia da indústria automobilística, incluindo-se a questão da modularização. Na seção 2, buscou-se realizar uma análise de características selecionadas da $\mathrm{P} \& \mathrm{D}$ e da evolução recente do processo de inovação tecnológica nesse setor. Finalmente, na seção 3 foram feitas algumas considerações finais, procurando relacionar os resultados obtidos neste artigo com a discussão do processo de de-maturity (rejuvenescimento) industrial, proposto por Abernathy e outros autores.

(3) Ver também Jones (1985); Watanabe (1987); Dertouzos et al. (1989).

(4) Ver ainda Fine et al. (1996); Freyssenet et al. (1998); Fujimoto (1999). 


\section{Tecnologia e modularização na indústria automobilística}

\subsection{Características tecnológicas básicas}

De acordo com a metodologia proposta pela OECD (2001) e pela UNCTAD (2005), o setor automobilístico deve ser classificado - com base nos seus atributos tecnológicos - como uma indústria de média-alta intensidade tecnológica, à semelhança dos setores de maquinaria elétrica, de química (exclusive farmacêutica), de máquinas e equipamentos mecânicos, de equipamentos ferroviário e de equipamentos de transporte não classificados em outras indústrias (OECD, 2001; UNCTAD, 2005). ${ }^{5}$ Muito embora seja verdade que a indústria automobilística e os automóveis se utilizem de várias tecnologias difundidas e de muitos sistemas e componentes familiares, é igualmente verdade que ambos também fazem amplo uso de um grande número de produtos e tecnologias avançadas, desenvolvidos através de intensas atividades de P\&D (ver Gráfico 1, a seguir, para os dados da indústria automobilística japonesa, e o Gráfico 1A do Anexo Estatístico, para informações sobre os países da OECD) (McAlinden et al., 2000; OTP, 2003a, 2003b; DOC, 2005, 2006). ${ }^{6}$ Como se verá adiante, os automóveis são também considerados produtos complexos, que se utilizam de processos produtivos e de uma base de conhecimento tecnológico igualmente complexos.

(5) Ainda segundo estas publicações, devem ser classificados como indústrias de alta tecnologia os setores de aviação e produtos espaciais; de produtos farmacêuticos; de computadores e maquinaria de escritório; de equipamentos de comunicação, rádio e televisão e de instrumentos médicos, óticos e de precisão (OECD, 2001; UNCTAD, 2005). Segundo UNCTAD (2005), os setores de alta tecnologia apresentam intensidade de $\mathrm{P} \& \mathrm{D}$ ( $\mathrm{P} \& \mathrm{D} /$ Vendas) acima de $5 \%$, enquanto os setores classificados como de média-alta intensidade tecnológica se situam na faixa entre $1,5 \%$ e $5 \%$. Destaque-se que, por esse critério, o setor automobilístico japonês deveria ser classificado como sendo de alta tecnologia (ver novamente o Gráfico 1).

(6) Por exemplo, de acordo com o U.S. Corporate R\&D: Volume I. Top 500 Firms in R\&D by Industry Category, o setor de veículos a motor e outros equipamentos de transporte de superfície foi o terceiro colocado sendo superado apenas pelos setores de eletrônica e informação e de substâncias e aparelhos médicos - tanto em termos da intensidade de $\mathrm{P} \& \mathrm{D}$ (relação $\mathrm{P} \& \mathrm{D} /$ Vendas) quanto dos gastos totais de Pesquisa e Desenvolvimento realizados em 1996 e 1997 pelas 500 maiores corporações da economia norte-americana (NSF, 1999, Quadros 1 e 4). Os dados desagregados por empresas do U.S. Corporate R\&D: Volume II. Company Information on Top 500 Firms in $R \& D$ revelam também que os gastos com P\&D (relação P\&D/Vendas) em 1996 e 1997 das duas maiores montadoras norte-americanas a GM $(4,8 \%$ e 5,5\%) e a Ford $(4,1 \%$ e 4,6\%) foram da mesma ordem de grandeza dos gastos correspondentes das duas maiores empresas do setor de aviões, mísseis guiados e de veículos espaciais, respectivamente a Boeing $(4,2 \%$ e 5,2\%) e a United Technologies Corp (4,8\% e 4,7\%). De fato, os gastos da GM foram até mesmo ligeiramente superiores (NSF, 1999, Quadro 3). 
Gráfico 1

Investimento em $\mathrm{P} \& \mathrm{D}$ dos fabricantes japoneses de veículos

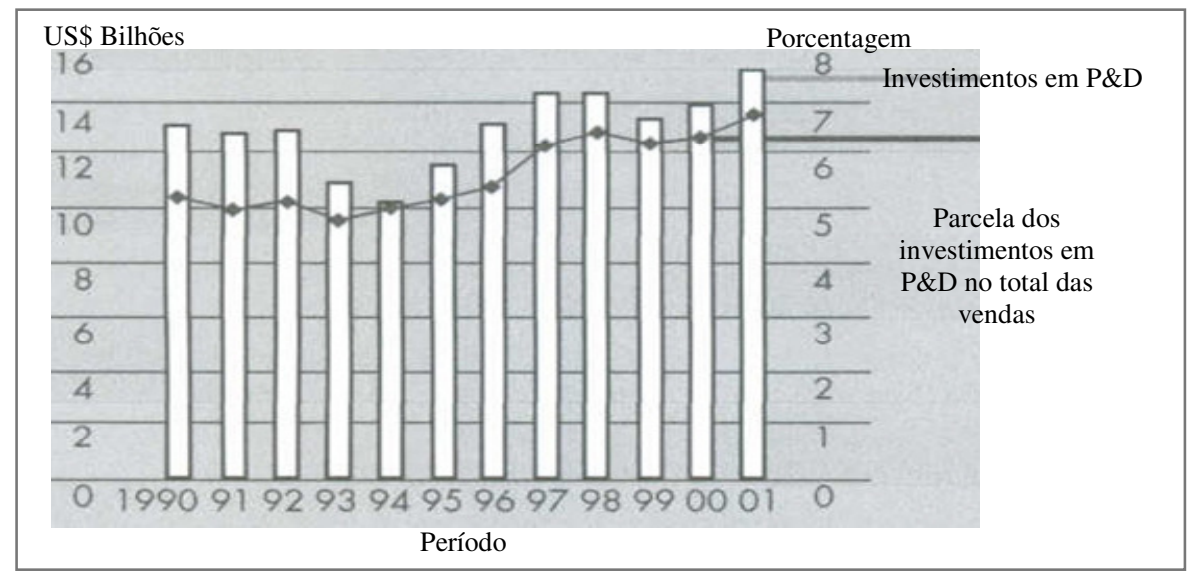

Fonte: OTP (2003a).

Com base no método proposto pelo U.S. Bureau of Census (BOC) para definir as indústrias high-tech, "o automóvel pode ser descrito como uma plataforma hospedeira de tecnologias de ponta e a indústria [automobilística] como uma produtora destas tecnologias" (McAlinden et al., 2000, p. 20). De fato, a indústria automobilística utiliza (ou desenvolve internamente) tecnologias de ponta e componentes de quatro áreas consideradas avançadas -1) computadores e telecomunicações, 2) eletrônica, 3) manufatura integrada por computadores e 4) design de materiais - de um total de dez que definiriam, segundo a metodologia sugerida pelo BOC, as indústrias de alta tecnologia (McAlinden et al., 2000).

No que se refere à utilização das novas tecnologias na indústria automobilística - excetuando-se, é claro, as formas alternativas de propulsão (motores elétricos, híbridos e células de combustível) -, a eletrônica ${ }^{7}$, a tecnologia de informação e os novos materiais são indiscutivelmente as variáveis-chave (McAlinden et al., 2000; Rapp, 2000; Chanaron, 2001; NRC, 2005). (Para uma visão mais detalhada das principais tecnologias de interesse na indústria automobilística ver o Quadro1A do Anexo Estatístico). Por exemplo, segundo estimativas, a parcela da eletrônica embarcada no custo corrente dos veículos automotores era de cerca de $10 \%$ em 2000 (McAlinden et al., 2000). ${ }^{8}$ Atualmente,

(7) Em sentido amplo, envolvendo não apenas a chamada eletrônica embarcada, mas também os sistemas $\mathrm{CAD} / \mathrm{CAM} / \mathrm{CAE}$, as flexible body lines, os sistemas CIM e os supercomputadores (EIU, $1^{\circ}$ quadrimestre de 1998).

(8) Para se dar uma idéia de quão efetivamente empenhado está o setor automobilístico em relação à utilização da eletrônica, uma outra estimativa desta mesma pesquisa parece ser esclarecedora: quase $85 \%$ (em termos de valor) dos produtos eletrônicos utilizados nos veículos leves produzidos nos Estados Unidos são fabricados dentro da própria indústria automobilística (McAlinden et al., 2000). 
avalia-se que tal parcela já seja de $20 \%$ e estima-se que ela salte para aproximadamente $40 \%$ em 2015 (DOC, 2006).

Como muitos outros setores, a indústria automobilística está expandindo rapidamente a utilização de sistemas e de componentes eletrônicos. Praticamente todas as funções dos autoveículos modernos sofisticados - como aceleração, frenagem, controles de tração, de estabilidade e de injeção de combustível (incluindo injeção eletrônica), sistemas de combustão lean-burn, dirigibilidade, segurança, ajuste da posição da direção e dos bancos, navegação, proteção antichoque, telemática, sistemas de controle de voz e entretenimento - já são controladas e/ou viabilizadas pela eletrônica embarcada (Fine et al., 1996; McAlinden et al., 2000; DOC, 2005 e 2006).

E a tendência em curso parece ser a crescente difusão desses controles eletrônicos para os veículos menos sofisticados - dependendo, é claro, da complexidade dos respectivos sistemas de controle e dos preços dos modelos -, em função da utilização cada vez mais intensa e ampla da eletrônica embarcada como arma competitiva ${ }^{9}$ e do barateamento relativo dos seus custos de produção (McAlinden et al., 2000; Carvalho, 2003; DOC, 2005 e 2006).

Por outro lado, a combinação da tecnologia da informação e da comunicação, em tempo real, de voz e de dados - que tem sido chamada de telemática - tem viabilizado o desenvolvimento de sistemas de navegação, de segurança e de serviços de emergência para os casos de acidentes e/ou de problemas mecânicos - incluindo notificação de roubo e rastreamento, diagnóstico mecânico remoto e banco de dados com informações médicas do motorista. ${ }^{10}$ Esses serviços resultam da combinação da telefonia móvel com os sistemas de posicionamento global para o monitoramento dos veículos (McAlinden et al., 2000; Rapp, 2000; DOE, 2000).

E o futuro próximo da telemática parece apontar para a viabilização de sistemas de controle de voz para várias funções do veículo - desenvolvido pioneiramente pela Visteon e já disponíveis, por exemplo, no Jaguar S-Type -, de informação de tráfico, em tempo real, e de acesso à internet no veículo. Para um horizonte de tempo mais amplo, as perspectivas mais promissoras para a telemática parecem estar associadas às possibilidades de desenvolvimento do que tem sido chamado de Sistema de Transporte Inteligente (ITS) (Fujimoto; Takeishi, 2001; McAlinden et al., 2000; Rapp, 2000).

(9) Uma recente estimativa concluiu que há entre 20 e 30 microprocessadores, em média, nos veículos automotores no mercado norte-americano (McAlinden et al., 2000). Já um Lexus LS 400, um modelo para o mercado de luxo da Toyota, tem 40 microcomputadores segundo a própria montadora (Chanaron, 2001).

(10) Atualmente o OnStar, oferecido pela GM, é o mais amplo serviço de telemática disponível no mercado norte-americano (McAlinden et al., 2000). 
A concepção atual do ITS é de que venha a ser possível, por exemplo, disponibilizar informações de engarrafamento de tráfico através da comunicação direta entre carros, entre carros e centros de controle e entre carros e rodovias. Imagina-se, ainda, que se venha a poder ajustar a distância entre os carros, em uma rodovia, através de controles automáticos, com o que os veículos funcionariam como virtuais unidades de um trem (Rapp, 2000; Fujimoto e Takeishi, 2001; NCR, 2003).

Se tais medidas forem efetivamente viáveis, os engarrafamentos nas rodovias expressas tenderiam a diminuir significativamente. $\mathrm{E}$ dadas as decorrentes possibilidades de aumentar a velocidade média dos veículos sem comprometer a segurança, diminuiriam também os gastos de energia. Ao mesmo tempo, seriam reduzidas as emissões de dióxido de carbono e os ganhos ambientais seriam potencialmente expressivos (Fujimoto; Takeishi, 2001; Rapp, 2000).

Tradicionalmente vista como uma indústria de aço e de ferro fundido, o setor automobilístico vem crescentemente também se empenhando no desenvolvimento e nas experiências com o uso de materiais leves ${ }^{11}$ - incluindo-se aços de alta e ultra-alta resistência, alumínio, plásticos especiais resistentes a altas temperaturas, ligas de magnésio e fibras compostas reforçadas (de carbono, cerâmicas e outros materiais). Estes esforços têm tido também impactos complementares consideráveis nos chamados processos de manufatura avançados (McAlinden et al., 2000; OTP, 2003b; NCR, 2003).

Segundo os resultados do Delphi X: Forecast and Analysis of the North American Automotive Industry (materials volume), os custos de produção seguem sendo os principais obstáculos à ampliação do uso dos materiais leves e, em particular, das fibras compostas reforçadas, não obstante o seu grande potencial como redutor de peso (McAlinden et al., 2000).

Atualmente estes materiais têm tido, ainda, uma utilização restrita aos veículos convencionais de alta performance e aos protótipos e modelos de pesquisa de alta milhagem, que têm sido desenvolvidos, no caso norte-americano, inicialmente no âmbito do USCAR e dos programas de tecnologias alternativas de powertrain (propulsores híbridos e de células de combustíveis) do Partnership for New Generation of Vehicles (PNGV) e, mais recentemente (desde 2004), no

(11) Essa busca por materiais novos e leves - que tem sido impulsionada no caso norte-americano pelo advento de novos mandatos governamentais relativos ao uso mais eficiente de combustíveis e pelas novas regulações quanto às emissões de poluentes (o Clean Air Act de 1990 e a 'lei 2004' da Califórnia) - tem envolvido não apenas as montadoras automobilísticas e os fornecedores de autopeças mas também os produtores de aço e a totalidade da infra-estrutura de pesquisa de que dispõem o U.S. Council for Automotive Research (USCAR), os laboratórios universitários e públicos de pesquisas e o American Iron and Steel Institute, através, neste último caso, do projeto do Ultralight Steel Auto Body (USLAB) (McAlinden et al., 2000). 
âmbito do FreedomCar e do Fuel Partnership (McAlinden et al., 2000; OTP, 2003b; NRC, 2005: The First Report. ${ }^{12}$

\subsection{Modularização e arquitetura}

Os automóveis são produtos tecnicamente $\operatorname{complexos}^{13}$ e de natureza sistêmica - sendo constituídos "por muitos elementos interdependentes e subsistemas, que sujeitam os modos do processo de aprendizado e a natureza das competências tecnológicas adquiridas pelas firmas" (Marsili, 2001, p. 172). Eles são também caracterizados pelo que tem sido chamado de uma arquitetura integral, isto é, "uma complexa relação entre as partes e as funções, o que requer que cada parte seja otimamente projetada para atingir o seu pleno desempenho" (Fujimoto e Takeishi, 2001, p. 3). ${ }^{14}$ Tais características impedem que o automóvel possa ser concebido integralmente em termos "modulares", 15 com interfaces padronizadas que permitam conectar os respectivos módulos aos veículos em operações únicas do tipo plug and play (Chanaron, 2001). ${ }^{16}$

Usualmente denomina-se arquitetura (integral ou modular) o projeto básico que divide o produto nas suas diferentes partes, que define as funções de cada uma delas e que determina como as mesmas serão unidas, interconectadas, formando um todo. A interconexão das partes é denominada de interface (Fujimoto; Takeishi, 2001).

A noção de arquitetura pode ser pensada, entretanto, a partir de duas dimensões básicas: uma no âmbito do produto e outra no das relações interfirmas.

(12) Em janeiro de 2004 foi instituído, por iniciativa presidencial, o FreedomCar para dar continuidade e ampliar o escopo de atuação do antigo PNGV (NRC, 2005).

(13) No sentido de que um amplo e profundo nível de expertise de engenharia é requerido para produzir um projeto que seja funcional e que viabilize que um grande número de partes funcionem juntas e de maneira precisa (Helper; Khambete, 2005). Por outro lado, segundo Hobday (1998) (citado por Marsili, 2001, p. 172) "Uma diferenciada base de conhecimento subjacente à inovação industrial reflete vários aspectos da complexidade dos produtos e/ou dos processos produtivos (...), onde um diferenciado perfil de competências tecnológicas emerge de produtos e processos produtivos complexos".

(14) "Por exemplo, considere-se o conforto de dirigir um carro. Delicados fatores, como uma diferença mínima na geometria da suspensão, ou se o eixo principal do motor está ligeiramente à frente ou atrás do eixo, podem influenciar significativamente o caráter geral do carro" (Fujimoto; Takeishi, 2001, p. 4).

(15) Pelo menos o automóvel atual com motor de combustão interna e com arquitetura de aço de $0,8 \mathrm{~mm}$ (Fujimoto, citado por Lynch, T. M. et al. 2000). Esta situação poderia, entretanto, mudar com o advento de novas tecnologias de propulsão dos autoveículos.

(16) "Não há uma única definição de módulo que possa ser aceita pelas montadoras e pelos fornecedores. Nas revistas profissionais, alguns estão usando módulo para designar o sistema de freios, outros para o chassi com as rodas ou mesmo para um veículo completo montado por um subcontratado. Um módulo poderia ser definido como um conjunto de componentes e/ou de subsistemas que são pré-montados fora da linha e entregues na linha final de montagem, prontos para serem colocados no veículo ou no motor em uma única operação, i. e., em uma abordagem 'plug and play'. Tal approach é nomeado de modular assembley" (Chanaron, 2001, p. 3). 
No âmbito do produto, emergem duas possibilidades arquitetônicas: a) a arquitetura modular, simples e com interface relativamente padronizada e b) a arquitetura integral, em que as relações entre partes e funções são mais complexas, o que exige que cada parte seja otimamente projetada para permitir o melhor desempenho do todo. No âmbito das relações entre empresas, surgem duas outras configurações arquitetônicas básicas: a) a arquitetura aberta, na qual o projeto do produto é realizado fora do domínio da firma e b) a arquitetura fechada, em que o mesmo é concebido no interior da empresa (Fujimoto; Takeishi, 2001).

O automóvel é um produto cuja arquitetura é integral e fechada. Sua complexidade deriva, por exemplo, de que uma pequena diferença na geometria da suspensão influencia significativamente o desempenho do produto. Para que funcione perfeitamente, cada parte componente deve ser otimamente projetada para esse tipo de produto. Assim, se a Toyota produz determinado carro, o projeto a ele relativo tem que ser basicamente realizado pela própria firma, de modo que as partes componentes do produto sejam, por sua vez, especificamente projetadas, conformando-se com o projeto em seu conjunto. Bicicletas, microcomputadores, equipamentos de som (e até certo ponto caminhões) são radicalmente diferentes. Seus produtos finais podem ser produzidos a partir da união de partes padronizadas compradas de terceiros (Fujimoto; Takeishi, 2001).

Mas, apesar dessa limitação estrutural comparativamente a outros produtos, tem se observado uma forte tentativa de modularização, desde a metade dos anos 1990, por parte das montadoras de automóveis ocidentais, especialmente as européias. Essa tendência tem sido concomitante com um forte movimento em direção à ampliação do outsourcing, também sendo implementada pelas montadoras ocidentais (Fujimoto; Takeishi, 2001; Sturgeon; Florida 1999; Vickery, 1996).

Neste último caso, as motivações parecem ser, principalmente, a possibilidade de beneficiar-se do relativamente mais baixo custo salarial enfrentado pelos fabricantes de autopeças e também para diminuir os riscos e o volume de investimentos necessários à ampliação das atividades, particularmente nos mercados dos países emergentes (Sturgeon; Florida, 1999; U.S. Industry \& Trade Outlook, 2000; Fujimoto; Takeishi, 2001).

A adoção dessas estratégias implica uma importante delegação de responsabilidades aos fornecedores dos módulos que passariam, assim, a assumir parte das funções de design e de manufatura e, conseqüentemente, a ter maior poder relativo dentro da cadeia produtiva. É, em grande medida, este último aspecto que faz com que as montadoras japonesas vejam a idéia de modularização de forma bastante mais cautelosa e limitada (Chanaron, 2001; Takeishi; Fujimoto, 2001). 
Segundo os experts japoneses, os principais obstáculos à modularização estão relacionados à administração dos custos, das competências e do processo de inovação. Segundo eles, não há evidências sólidas de que a modularização leve à redução sistemática de custos de produção - o diferencial de salários entre as montadoras e os fornecedores de autopeças no Japão é menor do que o enfrentado pelas montadoras ocidentais. Por outro lado, a modularização pode levar à criação de custos extras de sincronização entre as montadoras e os fornecedores de módulos (Chanaron, 2001).

Custos adicionais de transação poderiam, também, ser criados quando houvesse necessidade de mudança de fornecedor, bem como custos diretos extras seriam gerados se houvesse necessidade de introduzir mudanças significativas de design. Em ambos os casos, os custos adicionais seriam decorrentes da escolha de um único fornecedor que a modularização requer (Chanaron, 2001).

Um segundo obstáculo importante, também chamado de síndrome da caixa-preta, refere-se à potencial perda, por parte das montadoras, do tradicional conhecimento total dos custos reais, do lead time de desenvolvimento, da performance técnica e dos níveis de qualidade. "A Intel inside síndrome, traduzida por Bosch, Delphi (...) ou Sony inside síndrome [no caso da] indústria automobilística, seria então o limite extremo de tal movimento. Neste caso, o risco seria a completa reversão da imagem e do brand da montadora para um particular fornecedor" (Chanaron, 2001, p. 8).

Finalmente, haveria o risco de ter como fonte única, e numa relação de longo prazo, um fornecedor de módulo menos inovativo. Promover a competição entre os fornecedores potenciais é freqüentemente uma forma eficaz de incentivar a inovatividade dos mesmos (Chanaron, 2001; Takeishi; Fujimoto, 2001).

Coerentemente com essas preocupações, a Toyota e a Honda adotaram uma abordagem bastante cautelosa, introduzindo uma modularização parcial e sob o seu total controle, descartando uma maior re-engenharia das suas plantas assim como uma reorganização mais ampla de suas respectivas cadeias de fornecedores, especialmente no caso dos fornecedores afiliados (Chanaron, 2001; Takeishi; Fujimoto, 2001).

Em síntese, elas têm desenvolvido e fabricado os seus próprios módulos, que poderão, mais tarde, vir a ser produzidos pelos fornecedores afiliados, no caso da Toyota, ou pelos parceiros de longo prazo, no caso da Honda. As duas principais montadoras japonesas estão demonstrando que desejam liderar e controlar o processo, mantendo uma completa responsabilidade e controle pelo design e pelas core competências em todos os âmbitos que elas reputam como cruciais - o tecnológico, o produtivo e o estratégico (Fujimoto; Takeishi, 2001; Chanaron, 2001). 
Enéas Gonçalves de Carvalho

\section{P\&D e inovação tecnológica na indústria automobilística}

\subsection{Características selecionadas da P\&D na indústria automobilística}

A inovação na indústria automobilística é principalmente resultado dos processos de desenvolvimento de produto (Clark; Fujimoto, 1991; Marsili, 2001). ${ }^{17}$ Tal característica faz com que a organização das atividades de P\&D seja baseada principalmente em equipes de projeto e no crescente desenvolvimento simultâneo de parte das atividades dos respectivos projetos (Coriat; Weinstein, 2001; Fujimoto, 1999). Aparentemente, essa ênfase da P\&D no desenvolvimento de produtos pode ser, pelo menos em parte, a causa da predominância das inovações incrementais que têm caracterizado o setor automobilístico (Calabrese, 2001). ${ }^{18}$

Com relação à sua complexa base de conhecimento, às condições para o seu respectivo acesso às tecnologias-chave e às capacitações de uma maneira geral, a indústria automobilística parece combinar duas características fundamentais:

1) As capacidades inovativas são baseadas, principalmente, em capacitações específicas, coletivas e, em grande medida, tácitas e, portanto, de difícil codificação - desenvolvidas, por sua vez, através de processos de aprendizados coletivos e internos. Por esse motivo, a organização interna do desenvolvimento de produto e as suas relações com as outras funções (de design, de produção, de marketing, etc.) das montadoras têm se revelado críticas. Não por acaso, o management dos recursos humanos internos parece estar na base do sucesso das concepções organizacionais/produtivas da Toyota (Teece et al., 1997; Fujimoto, 1999; Coriat; Weinstein, 2001).

2) A natureza sistêmica de sua complexa base de conhecimento e o aspecto central do design system nos processos de desenvolvimento de produtos. Tais fatos parecem conferir um papel crítico às condições de acesso das montadoras às diferentes fontes de conhecimento, de tecnologias e de informações, especialmente

(17) Segundo os dados da NSF para 1992, os gastos com o desenvolvimento de produto na indústria automobilística norte-americana respondiam por $91,7 \%$ do total de gastos em $\mathrm{P} \& \mathrm{D}$, cabendo à pesquisa aplicada e à básica 7,1\% e 1,2\% respectivamente (Marsili, 2001).

(18) Poderia se acrescentar, neste caso, a relativa maturidade das principais tecnologias automobilísticas. Essa situação tem, entretanto, se alterado, no caso da tecnologia dos motores de combustão interna, em razão, principalmente, da intensificação do uso da microeletrônica (sensores) no desenvolvimento dos motores, e também pelos avanços nas novas tecnologias de propulsão dos autoveículos (especialmente, motores elétricos híbridos e as células de combustível) (OTP, 1998; OTP, 2003a, 2003b; Marsili, 2001; DOC, 2005, 2006). 
em relação aos fornecedores de equipamentos (Coriat; Weinstein, 2001; Raap, 2000, 2001; Marsili, 2001) ${ }^{19}$ (ver também a próxima nota).

Com respeito à dimensão organizacional da $\mathrm{P} \& \mathrm{D}$, cabe destacar que a organização por projetos e, em particular, a estrutura de heavyweight team, tem se mostrado a forma mais eficiente tanto em termos dos custos quanto do tempo necessário para o desenvolvimento e a introdução de novos modelos (Clark; Fujimoto, 1991; Iansiti; Clark, 1994). Essa forma de coordenação interna tem sido combinada também com novos métodos quanto às relações externas com fornecedores, especialmente quando envolvem atividades cooperativas (Teece et al., 1997; Fujimoto, 1999).

Quanto aos fatores determinantes da eficiência da P\&D, deve ser enfatizado o papel central das condições em que se processa a coordenação das atividades do corpo técnico que, por sua vez, viabiliza os processos de aprendizado coletivo interno (Clark; Fujimoto, 1991; Iansiti; Clark, 1994). Especialmente importantes parecem ser, também, a coesão das equipes de desenvolvimento e a sua interação com os demais grupos constituintes das empresas (Teece et al., 1997; Fujimoto, 1999; Coriat; Weinstein, 2001).

Por outro lado, "enquanto integradores de sistemas, os fabricantes de automóveis contam com fornecedores externos de partes e componentes o que, freqüentemente, requer elevados níveis de esforços em P, D \& E. Profundo conhecimento tecnológico é necessário para o controle estratégico sobre os fornecedores e os acordos conjuntos de P, D \& E” (Miller, 1994, p. 31).

Como as pesquisas recentes têm demonstrado, a principal fonte de acumulação de conhecimento tecnológico no caso da indústria automobilística se baseia - mais do que na absorção externa de novas tecnologias, mesmo quando essa possibilidade está disponível (como tem ocorrido recentemente) -

(19) O regime tecnológico dos sistemas complexos de conhecimento [the complex (knowledge) system (techonological) regime]

- constituído pelas indústrias automobilística e aeroespacial) - "apresenta um alto grau de diferenciação tecnológica na base de conhecimento. (...) Nestas indústrias, a inovação envolve tipicamente uma ampla gama de tecnologias através de diversas áreas de conhecimento. Particularmente diferenciado é o conjunto de competências de background nas tecnologias de produção, revelando a natureza altamente complexa da cadeia de fornecimento. Em ambas as indústrias de transporte, as competências de background são desenvolvidas em instrumentos, computadores, aparelhos elétricos e equipamentos, equipamento de metalurgia e produtos metálicos" (Marsili, 2001, p. 169). No caso do setor automobilístico as core competências são em tecnologias de veículos rodoviários e motores e maquinaria não elétrica. Em termos da distribuição do total de patentes obtidos no USPTO, entre 1981 e 1990, pelas empresas automobilísticas da amostra de 539 grandes firmas do SPRU (Sussex Universty), as mencionadas core tecnologias respondem por, respectivamente, 21,4\% e 15,2\% (Marsili, 2001, p. 125). 
principalmente na habilidade das próprias firmas de desenvolverem internamente capacitações organizacionais específicas. Não obstante, as montadoras também fazem uso complementar de uma extensiva rede de fornecedores de tecnologia (Miller, 1994; Marsili, 2001). Entretanto, as empresas tecnologicamente líderes são relativamente independentes da sua rede de tecnologia: "Elas definem a si próprias como as fontes primeiras de novas tecnologias" (Miller, 1994, p. 32; Carvalho, 2005b).

A eficiência desse tipo de sistema de inovação e de produção, como demonstram em especial os estudos sobre as montadoras japonesas e alemãs, parece estar fortemente relacionada com a criação de rotinas específicas no interior das empresas e com as respectivas estratégias de administração do trabalho e de incentivos (Clark; Fujimoto, 1991; Teece et al., 1997; Fujimoto, 1999).

Em termos do regime tecnológico, ${ }^{20}$ a indústria automobilística pode ser caracterizada por um médio-alto grau de oportunidade, ${ }^{21}$ por um médio-alto grau de barreiras à entrada em conhecimento e escala, por uma elevada persistência da inovação em tecnologias, pela complexidade da sua base de conhecimento e, também, por elevadas cumulatividade e apropriabilidade (Marsili, 2001; Malerba, 2001). Com relação às condições de apropriabilidade das inovações, o lead time muito mais do que as patentes ${ }^{22}$ (Calabrese, 2001; Marsili, 2001) - tem se revelado

(20) Segundo Malerba, um regime tecnológico é caracterizado pelas condições de oportunidade, de apropriabilidade e pelos graus de cumulatividade do conhecimento tecnológico e, também, pelas características da sua base relevante de conhecimento (Malerba; Orsenigo, 1996; Malerba, 2001). Mais recentemente, Marsili propôs uma ampliação da noção de regime tecnológico caracterizando-o em termos do "nível de oportunidade tecnológica, do peso das barreiras tecnológicas à entrada derivadas da especificidade da indústria em relação ao conhecimento e às vantagens de escala em inovação, da persistência da inovação, da diversidade tecnológica intra-industrial entre as firmas, do nível e direções da diferenciação da base de conhecimento, da relevância das fontes externas de conhecimento, das ligações com a pesquisa acadêmica em vários campos do conhecimento e da natureza da inovação" (Marsili, 2001, p. 93).

(21) Como se está procurando demonstrar (ver adiante), o grau de oportunidade tecnológico da indústria automobilística vem se elevando, nos anos recentes, em função das novas possibilidades de introdução de inovações viabilizadas, principalmente, pelos avanços da microeletrônica, das tecnologias de motores de combustão interna e, mais recentemente, pelas inovadoras tecnologias de propulsão de autoveículos (Marsili, 2001; OTP, 200 a, 2003b; NRC, 2005; DOC, 2005, 2006).

(22) Analogamente ao aeroespacial, o setor automobilístico também tem uma baixa propensão a patentear. Considere-se o seguinte exemplo: na classificação da intensidade inovativa, elaborada a partir do banco de dados das grandes firmas do SPRU para o período de 1985-90, o setor automobilístico figurava em $10^{\circ}$ lugar quanto à intensidade do patenteamento e em $6^{\circ}$ lugar em termos da intensidade da $\mathrm{P} \& \mathrm{D}-\mathrm{o}$ setor aeroespacial figurava em $7^{\circ}$ e em $5^{\circ}$ lugares, respectivamente, em relação à intensidade do patenteamento e do gasto em P\&D. Isso demonstra que o esforço inovativo, tanto da indústria automobilística quanto da aeronáutica, tende a ser subestimado pelos dados de patenteamento, sendo, por outro lado, mais apropriadamente avaliado pela intensidade dos gastos em P\&D. Não obstante, é digno de destaque que o setor automobilístico figurava em $4^{\circ}$ lugar no ranking quando se considerava o peso relativo dos diferentes setores, da referida amostra de grandes 
como o mecanismo mais eficaz de proteção no âmbito da inovação de produtos. Esta última característica parece estar também fortemente relacionada à importância que a redução do tempo de desenvolvimento de produtos vem crescentemente adquirindo, como arma competitiva, no setor automobilístico (Fujimoto; Takeishi, 2001; DOC, 2005, 2006).

De fato, a intensificação da concorrência na indústria automobilística tem sido marcada pela utilização mais intensa da tecnologia (especialmente da microeletrônica) (Vickery, 1996; Fine et al., 1996), pela redução do ciclo de desenvolvimento de produto (Fujimoto, 1999; Fujimoto; Takeishi, 2001), pela ampliação da diversidade de modelos (e dos seus atributos) e pela segmentação dos mercados previamente existentes (NRC, 2003; OECD, 2004; DOC, 2005, 2006). No caso dos EUA, por exemplo, as vendas anuais médias por modelo caíram de 106,8 mil em 1985 para 48,6 mil em 2005. Por outro lado, o número de modelos de carros oferecidos naquele mercado, que era de cerca de 250 em 1999, deverá subir para estimados 330 em 2008. Além de uma maior diversidade de modelos, tem sido incorporado também um crescente número de atributos e capacidades aos mesmos (DOC, 2005, 2006).

$\mathrm{Na}$ mesma direção, os dados de patentes, obtidos por montadoras selecionadas junto ao USPTO e sistematizados por este autor, parecem corroborar também, nesse âmbito, a idéia da intensificação do uso da tecnologia e, indiretamente, da intensificação da concorrência (ver Gráfico 2 a seguir).

empresas, em termos das suas participações no total das patentes obtidas nas áreas tecnológicas com mais rápido crescimento. O setor automobilístico possuía, segundo esse ranking, 23,8\% de patentes das áreas tecnológicas de mais rápido crescimento, no número total de suas patentes obtidas. Nesse relevante quesito, a indústria automobilística era superada apenas pelas indústrias de computadores, de instrumentos e de eletroeletrônicos, respectivamente $\left(1^{\circ}, 2^{\circ}\right.$ e $3^{\circ}$ lugares), ficando à frente, por exemplo, da farmacêutica $\left(5^{\circ}\right)$, da química $\left(7^{\circ}\right)$ e, particularmente, da aeronáutica $\left(12^{\circ}\right)$ (Marsili, 2001, p. 117). 
Enéas Gonçalves de Carvalho

Gráfico 2

Patentes obtidas no USPTO pelas montadoras selecionadas, agrupadas por região (1990 a 2005)

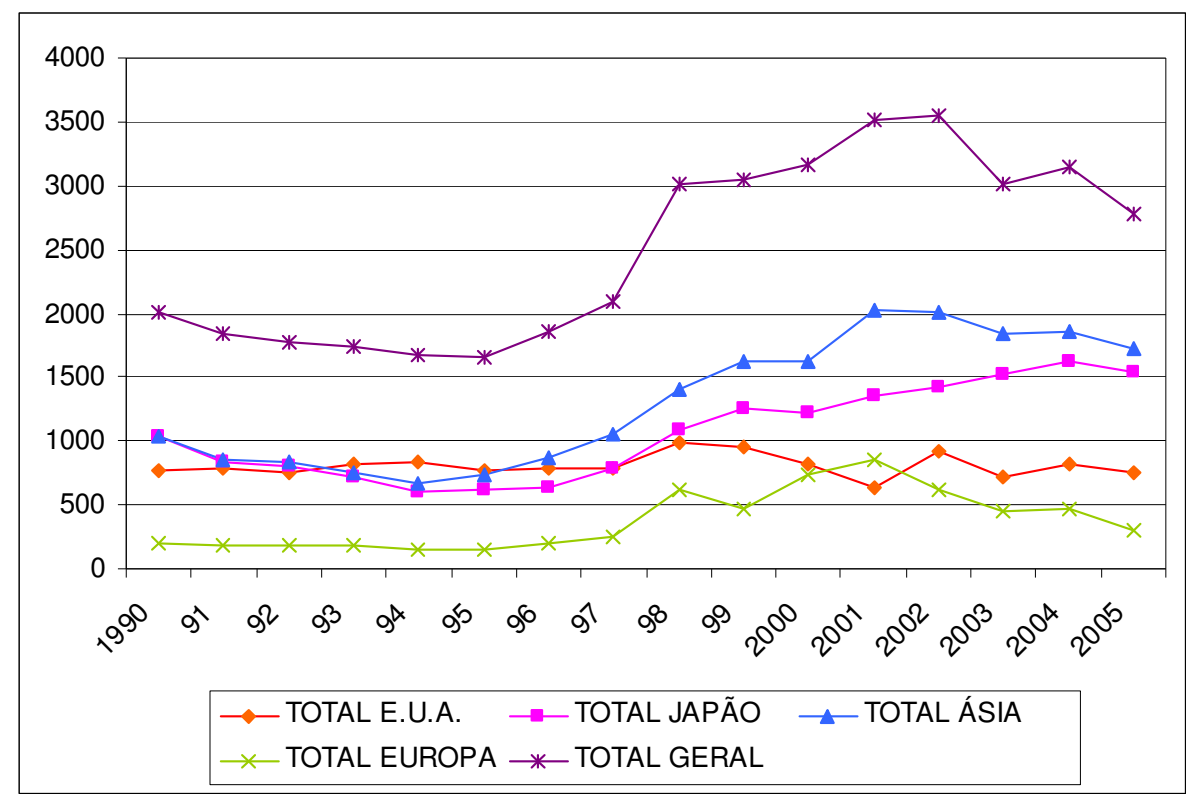

Fonte: Elaborado pelo autor a partir de Informações do USPTO (ver Tabela 2A, do Anexo).

Por outro lado, tem-se observado, mais recentemente, também uma importância crescente atribuída ao desenvolvimento das novas tecnologias de propulsão dos autoveículos como arma competitiva potencialmente estratégica (DOC, 2005 e 2006; OTP, 2003 a e b; NRC, 2005). Essa informação parece ser corroborada também pelos dados dos Gráficos 3 e 4 , a seguir. 
Gráfico 3

Atividade das famílias de patentes de célula de combustível automotiva (1983 a 2001)

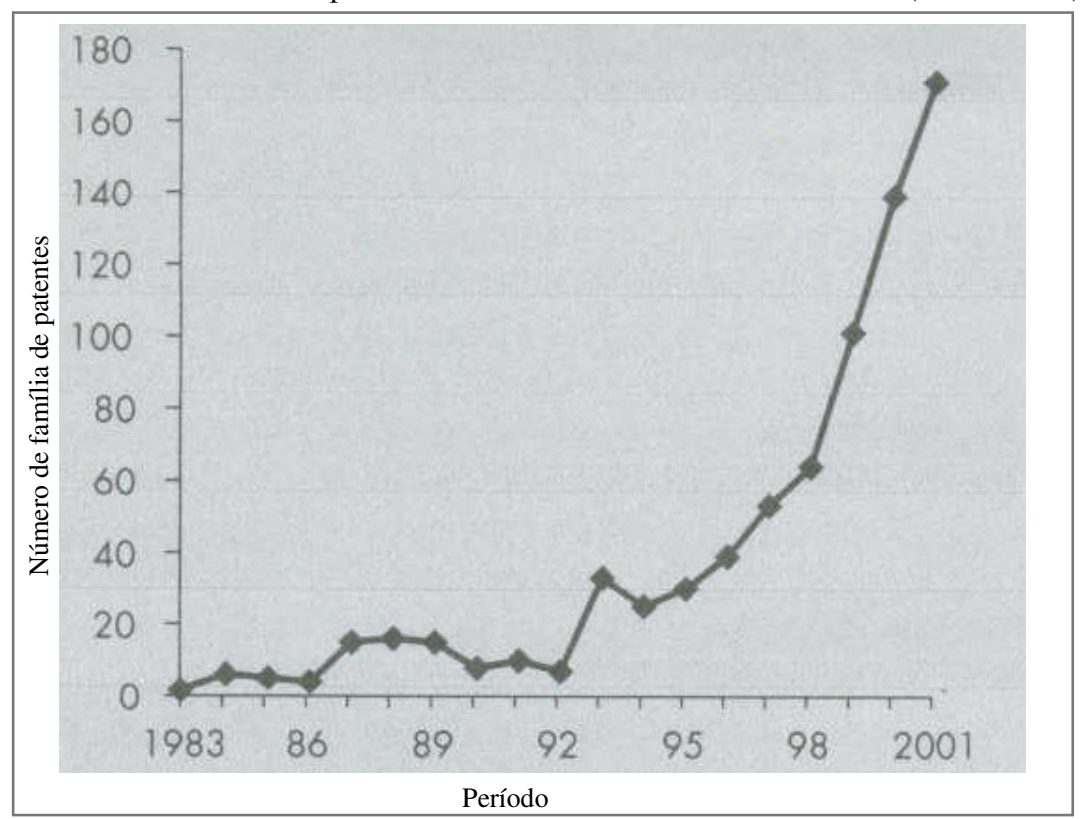

Fonte: OTP (2003a).

Gráfico 4

Comparação da atividade das famílias de patentes em tecnologias automotivas avançadas

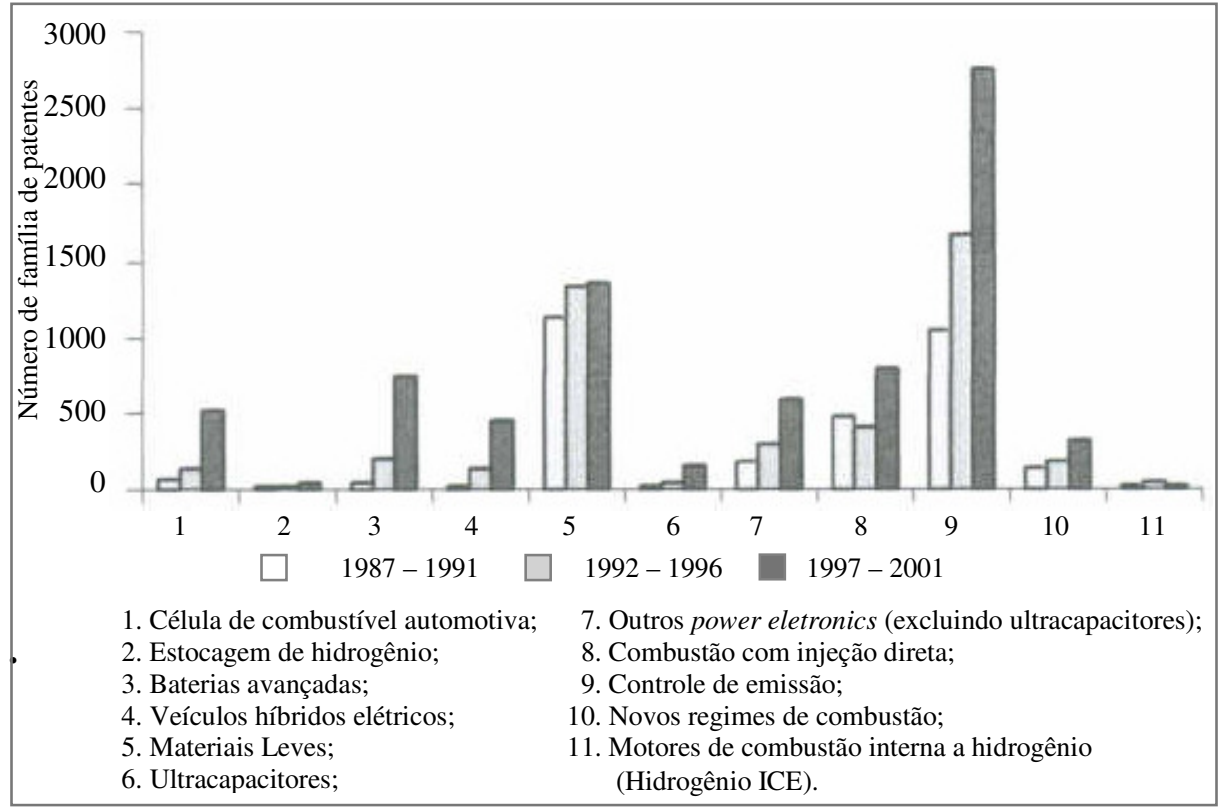

Fonte: OTP (2003b). 
Enéas Gonçalves de Carvalho

\subsection{Inovação tecnológica: evolução recente}

No âmbito propriamente tecnológico, estas últimas décadas na indústria automobilística têm sido caracterizadas:

I) Por um aumento tendencial (ainda que com oscilações cíclicas) dos gastos com P\&D - ver novamente o Gráfico 1, para os dados da indústria automobilística japonesa, e o Gráfico 1A do Anexo Estatístico, para os dados sobre os países da OECD (Vickery, 1996; OTP, 2003a).

II) Por uma ampliação na obtenção do número de patentes (particularmente a partir de 1995) -ver novamente o Gráfico 2 e a Tabela 1, para informações das montadoras de veículos selecionadas e do setor automobilístico norte-americano, respectivamente, e o Gráfico 2A e a Tabela 2A do Anexo Estatístico, para informações das principais regiões (OTP, 1998; NRC, 1998; OTP, 2003a, 2003b).

III) Por uma utilização crescente, e cada vez mais generalizada, da microeletrônica, tanto nos processos produtivos quanto no automóvel em si (Vickery, 1996; Fujimoto; Takeishi, 2001; DOC, 2005, 2006). ${ }^{23}$

À primeira vista, o padrão de introdução de inovações da indústria automobilística poderia ser apropriadamente caracterizado pela assim chamada creative accumulation - com o predomínio de grandes empresas estabelecidas e pela existência de significativas barreiras à entrada relativamente aos potenciais inovadores entrantes (Malerba, 2001; Marsili, 2001). Esse regime de inovação (que já se tornou conhecido como Schumpeter Mark II) é também caracterizado por indústrias maduras - que apresentam importantes economias de escalas e curvas de aprendizado significativas -, nas quais a mudança tecnológica se desenvolve, em geral, segundo trajetórias bem conhecidas e fundamentalmente através de inovações incrementais de produtos e de processos (Malerba, 2001; Marsili, 2001; Coriat; Weinstein, 2001). ${ }^{24}$

Em setores como o automobilístico - como já havia sido destacado por Abernathy e Utterback (1978) -, as grandes empresas (com forte poder oligopolístico e financeiro) estão, em geral, em posição de liderança em seus mercados e nos respectivos processos de mudança tecnológica. Tipicamente, essas posições de destaque foram conquistadas ao longo dos respectivos processos de

(23) Ver também Jones (1985); Watanabe (1987); Womack et al. (1990).

(24) O denominado regime de inovação Schumpeter Mark I é caracterizado pela chamada 'destruição criativa', pela ausência de importantes barreiras tecnológicas à entrada e pelo papel preponderante desempenhado pelos entrepreneurs e pelos novos entrantes nas atividades inovativas. Elevadas oportunidades tecnológicas, baixos níveis de apropriabilidade e de cumulatividade e um limitado papel do conhecimento genérico também são dimensões características do padrão de atividades inovativas Schumpeter Mark I. "No início da história de uma indústria, quando o conhecimento está mudando muito rapidamente, a incerteza é muito alta e as barreiras à entrada são muito baixas, as novas firmas são as principais inovadoras e os elementos chave na dinâmica industrial" (Malerba, 2001, p. 12). 
desenvolvimento dos chamados designs dominantes ${ }^{25}$ (Utterback, 1996; Freeman; Soete, 1997).

O ponto a ser destacado aqui é que a indústria automobilística parece ter se afastado recentemente, ao menos em parte, desse padrão anteriormente assinalado (ver a Tabela 1, a seguir, e novamente os Gráficos 1 e 2; os dados apresentados na última nota da seção anterior (2.1) parecem também ser exemplos ilustrativos dessa mesma relativa mudança). A intensificação da concorrência e a maior oportunidade tecnológica associada aos avanços na tecnologia do motor a combustão interna, ${ }^{26}$ às novas tecnologias microeletrônica, de materiais, de informação e, mais recentemente, às emergentes - e inovadoras - técnicas de propulsão dos autoveículos (ver novamente os Gráficos 3 e 4) parecem ter dinamizado o comportamento tecnológico da indústria automobilística, colocando em pauta a questão da eventual ocorrência de um processo de de-maturity (rejuvenescimento) industrial - nos termos originalmente propostos por Abernathy et al. (1983) e Abernathy e Clark (1985) (ver as Considerações finais).

Tabela 1

Crescimento do total de patentes norte-americanas por setor

\begin{tabular}{l|c|c|c}
\hline \multirow{2}{*}{\multicolumn{1}{c|}{ Setores }} & \multicolumn{2}{c|}{ Número de Patentes } & Crescimento \\
\cline { 2 - 3 } & 1982 & 1996 & (em porcentagem) \\
\hline Materiais Avançados $^{1}$ & 250 & 1.200 & +333 \\
\hline Tecnologia de Informação $^{2}$ & 4.000 & 16.000 & +305 \\
\hline Saúde $^{3}$ & 2.000 & 4.700 & +189 \\
\hline EPTL $^{4}$ & 600 & 1.500 & +151 \\
\hline Automotivo $^{5}$ & 1.300 & 2.700 & +105 \\
\hline Total das patentes norte-americanas $^{*}$ & 58.000 & 110.000 & +89 \\
\hline
\end{tabular}

Nota: ${ }^{1}$ Incluindo cerâmicas; ligas de alumínio, compósitas, membranas, biomateriais, supercondutores de alta temperatura e polímeros selecionados; ${ }^{2}$ Incluindo hardware e software; ${ }^{3}$ Incluindo drogas, remédios, biotecnologia (inclui engenharia genética de drogas, testes imunológicos e diagnósticos). Aparelhos médicos não incluídos. ${ }^{4}$ Transporte de encomendas e logística; ${ }^{5}$ Incluindo tecnologias de motores, de transmissões, de suspensões, de breques, de rodas e de pneus, do corpo do veículo e do chassi, das acomodações dos passageiros e de segurança, de controle de poluição e de manufatura automotiva. Fonte: OTP (1998).

(25) "Uma inovação radical inicial de produto leva a muitos novos entrantes e a vários designs concorrentes. Inovações de processos e o scaling up da produção levam, então, à emergência de um robusto design dominante, à erosão das margens de lucro e a um processo de mergers e falências, resultando em uma estrutura oligopolística com poucas firmas. Inovações incrementais tendem, então, a prevalecer em produtos e em processos" (Freeman; Soete, 1997, p. 146).

(26) De acordo com os dados de patentes obtidas no USPTO (1981-1994) - classificados dentro de 34 áreas tecnológicas, segundo a metodologia do SPRU para caracterizar as diferentes tecnologias em termos da taxa de mudança de longo prazo -, a área de veículos rodoviários e motores apresentou, para o período em questão, uma taxa de crescimento de $50,7 \%$, obtendo assim a $7^{\mathrm{a}}$ posição do ranking das 34 áreas tecnológicas com mais rápido crescimento. Num nível de maior desagregação (91 subáreas tecnológicas), a subárea de motores de combustão interna apresentou uma taxa de crescimento, para o período, ainda mais expressiva: $62 \%$. Destaque-se, para efeito comparativo, que a taxa de crescimento do total da amostra de patentes foi de 18,2\% (Marsili, 2001, p. $121,123)$. Note-se, ademais, que estes últimos dados são consistentes, do ponto de vista que se quer destacar aqui, com as informações apresentadas, anteriormente, na Tabela 1). 
Caberia destacar, ${ }^{27}$ por outro lado, que o setor automobilístico tem demonstrado - no que tange aos gastos relativos em $\mathrm{P} \& \mathrm{D}$, no âmbito da indústria manufatureira em geral - um desempenho comparado surpreendente, para um setor que usualmente não aparece entre os mais intensivos em tecnologia. De fato, como mostra o Quadro 1 a seguir, o setor automobilístico tem, sistematicamente, figurado nas primeiras posições, em termos de gastos em P\&D, e mantido uma participação estável (no caso japonês) ou moderadamente crescente (nos casos norte-americano e da União Européia) no total de gastos (crescentes) em P\&D do conjunto da indústria manufatureira (NSF, 2004, 2006). ${ }^{28}$

Para qualificar ainda melhor o ponto, destaque-se, no caso norteamericano, por outro lado, as significativas quedas - em termos de participação relativa nos gastos manufatureiros totais em $P \& D$ - de dois setores intensivos em tecnologia: o aeroespacial e o de computadores e de hardware de escritório. No que tange, por sua vez, à intensidade dos gastos em P\&D, o setor automobilístico norte-americano tem apresentado um comportamento relativo moderadamente favorável, como pode ser visto no Quadro 2 e no Gráfico 6 abaixo e nas Tabelas 3A e 4A do Anexo Estatístico.

(27) A comparação que se segue da indústria automobilística com a indústria manufatureira em geral e com o setor aeroespacial, no caso norte-americano em especial, teve por propósito afastar a hipótese de que a maior intensidade da P\&D do setor automobilístico, nos anos recentes, seria apenas resultado de uma tendência geral da indústria, produzida e propiciada pela incorporação das novas tecnologias microeletrônica e de informação. A comparação específica com a indústria aeroespacial é justificada por duas razões principais: o fato de o setor aeroespacial ser de alta tecnologia e de ter fortes semelhanças com o automobilístico, em termos do regime tecnológico (ver, novamente, Marsili, 2001, p. 125).

(28) No caso norte-americano, o setor automobilístico figurou, no primeiro período (1990-2000), em $4^{\circ}$ lugar, mas com participação relativa crescente; no segundo período (2001-2003), figurou sucessivamente em $3^{\circ} \mathrm{e}$ $2^{\circ}$ lugares e com participação relativa também crescente. No caso japonês, ocupou estavelmente a $3^{\mathrm{a}}$ posição, com participação relativa também praticamente estável. E no caso da UE, ocupou o segundo lugar, mas com participação relativa crescente (ver Quadro 1). 
Quadro 1

Participação de setores selecionados na P\&D industrial no total da manufatura

(EUA, Japão e União Européia)

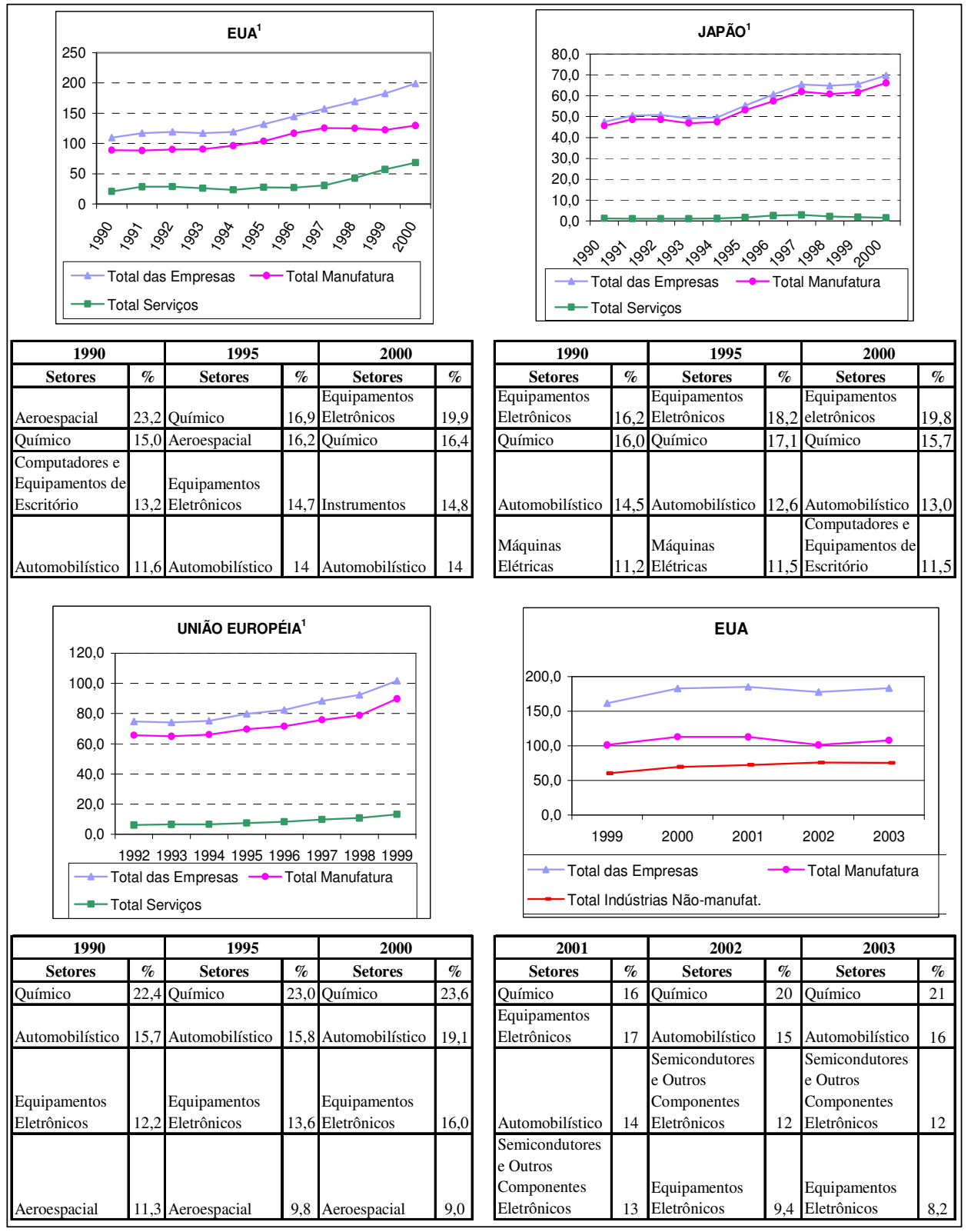

Notas: ${ }^{1}$ US\$ Bilhões PPC; EUA (1999-2003): US\$ Bilhões. Os dados relativos aos dois períodos dos EUA não são estritamente comparáveis.

Fonte: Elaborado pelo autor a partir de NSF: Science and Engineering Indicators (2004, 2006). 
Enéas Gonçalves de Carvalho

Quadro 2

Intensidade da $\mathrm{P} \& \mathrm{D}$ industrial ( $\mathrm{P} \& \mathrm{D} /$ vendas líquidas) das empresas norte-americanas (exceto fundos federais), por setor, nos períodos de 1987-1991 e 1992-1996
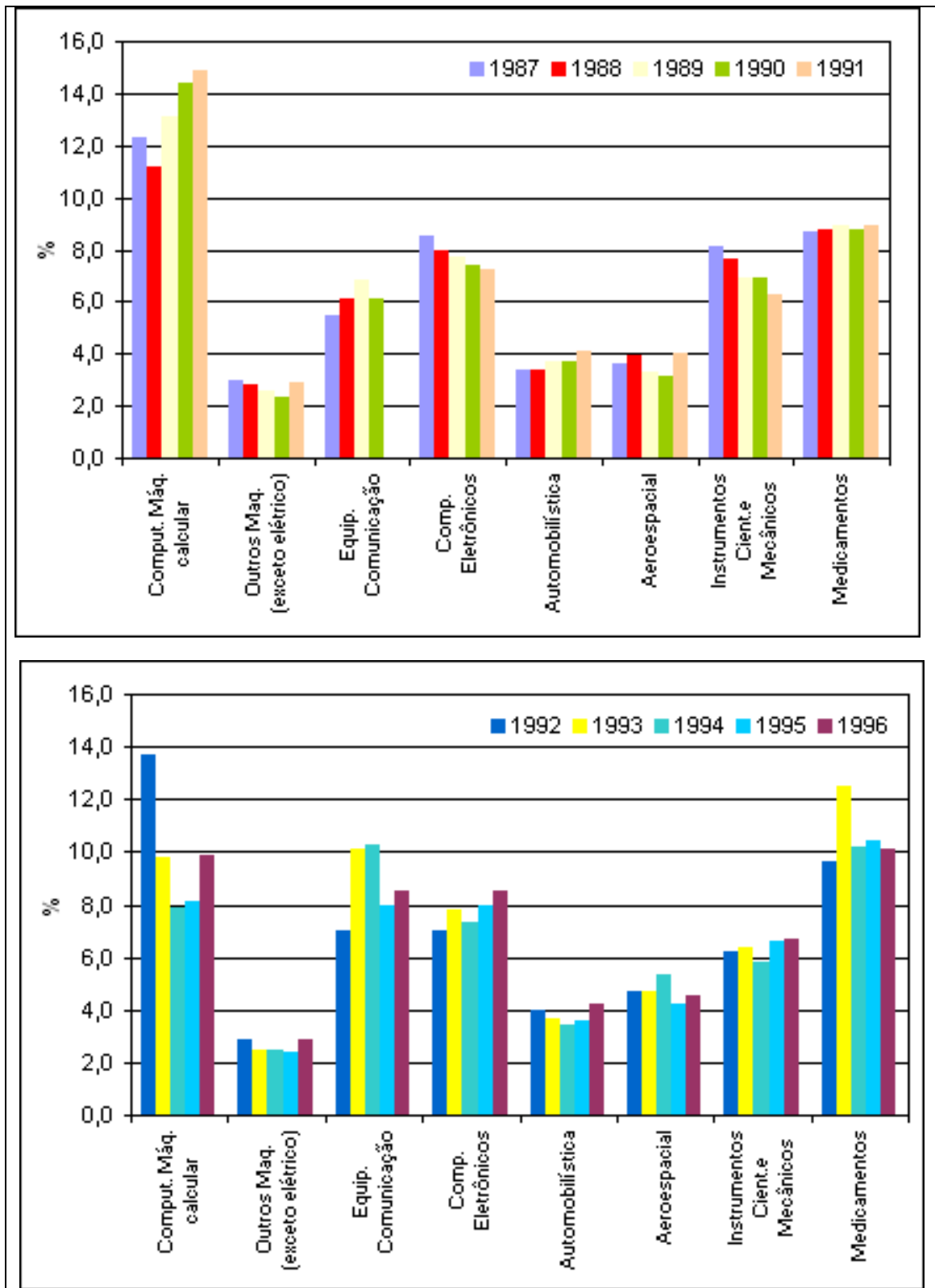

Fonte: Ver a Tabela 3A do Anexo Estatístico.

De fato, no qüinqüênio 1987-1991, o setor automotivo norte-americano apresentou um desempenho relativo, em termos da intensidade da P\&D, caracterizado por uma elevação razoável se comparado tanto aos gastos do Total 
da Manufatura quanto ao desempenho do setor aeroespacial: neste qüinqüênio, a intensidade média do primeiro setor foi superior à do segundo. No qüinqüênio 1992-1996, o setor automotivo continuou elevando a intensidade média dos gastos em P\&D (3,8\% em comparação com 3,6\% do período anterior), mas voltou a ser superado pelos gastos médios do setor aeroespacial (4,7\%). Manteve-se, porém, com um desempenho superior aos gastos médios do Total da Manufatura. A intensidade média dos gastos do setor automotivo em P\&D no qüinqüênio 19972001 foi menos elevada $(3,1 \%)$ do que nos subperíodos anteriores, mas ainda assim ligeiramente superior à média do setor aeroespacial $(3,0 \%)$ (ver Quadro 2, Gráfico 6 e as Tabelas 3A e 4A do Anexo Estatístico).

Gráfico 6

Intensidade da $\mathrm{P} \& \mathrm{D}$ industrial ( $\mathrm{P} \& \mathrm{D} / \mathrm{vendas}$ líquidas) das empresas norte-americanas (exceto fundos federais), por setor (1997-2001)

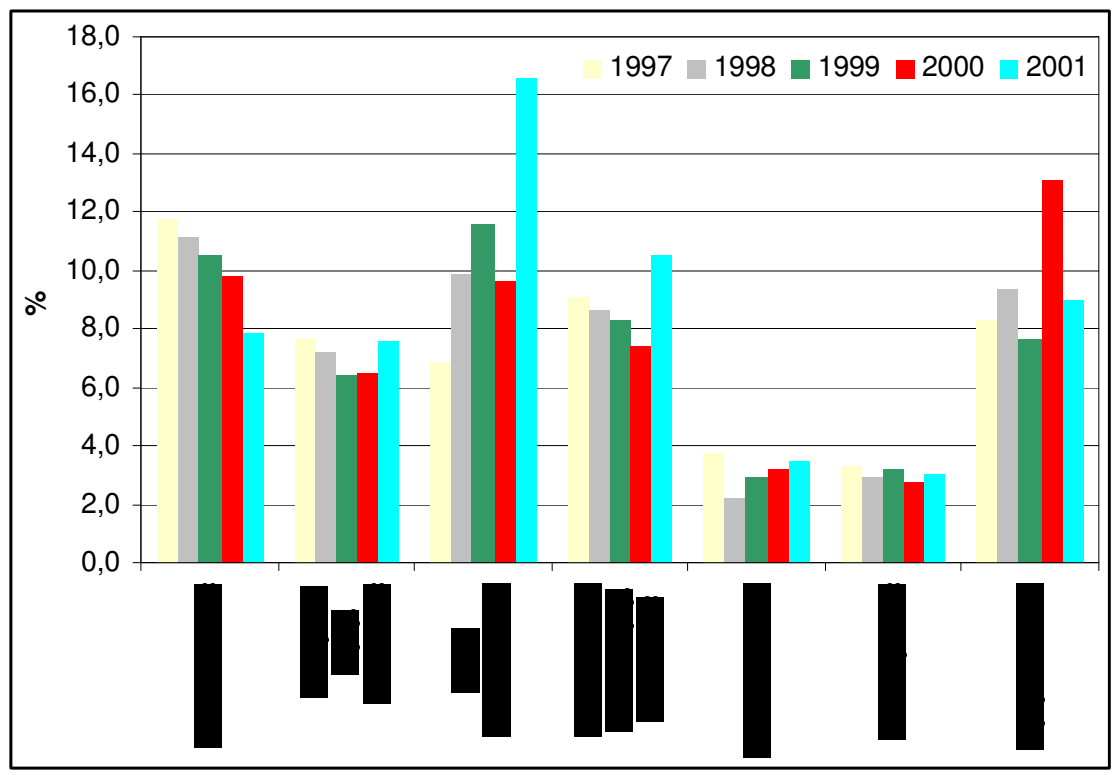

Fonte: Ver a TABELA 4A do Anexo Estatístico.

Convém relembrar, também, para efeito do argumento aqui em pauta, que a intensidade da P\&D do setor automobilístico japonês, como ficou evidenciado no Gráfico 1, tem sido significativamente mais elevada do que a do norteamericano, o que, por um lado, aumenta o desempenho médio global do setor automobilístico e, por outro, justificaria classificar o setor automotivo japonês na categoria de elevada intensidade tecnológica (ver novamente o subitem $1.1 \mathrm{e}$, especificamente, a nota 5).

Como, por outro lado, a necessidade de ter que substituir a atual forma de propulsão dos autoveículos parece quase certa, já se encontra em andamento uma 
verdadeira corrida tecnológica para se determinar, entre as alternativas possíveis, os meios mais eficientes e economicamente viáveis para se realizar a referida substituição. Com efeito, a 'lei 2004', já adotada pelo Estado da Califórnia (e por vários outros estados da região nordeste dos Estados Unidos), parece mesmo condenar o motor de combustão interna à extinção. Ao estabelecer que, a partir de 2007, pelo menos $10 \%$ das unidades vendidas por cada fabricante, naquele estado, seja de veículos de emissão zero, a 'lei 2004' introduz uma exigência que nem mesmo o mais limpo motor de combustão interna poderia atingir. Assim, como a expectativa, na avaliação dos analistas e das próprias montadoras, é de que tais normas regulatórias tendam a se difundir (e a se tornar cada vez mais estritas), a viabilização de uma nova tecnologia que atenda a tais requisitos está se convertendo numa questão estratégica para as montadoras (NRC, 2001, 2005).

Essa corrida tecnológica, que não se limita às montadoras e aos fabricantes de autopeças, ${ }^{29}$ poderá ter implicações bastante significativas para o automóvel e para a indústria automobilística de uma maneira geral ${ }^{30}$ (McAlinden et al., 2000; NRC, 2003, 2005; NAS, 2004).

Embora a indústria automobilística internacional venha passando por várias e importantes mudanças nos anos recentes (Fine et al., 1996; Fujimoto, Takeishi, 2001), nenhuma delas apresentou um potencial de transformações tão amplo quanto parece ser o caso das mudanças tecnológicas que provavelmente emergirão, no futuro relativamente próximo, em resposta à atual tendência ambientalista por veículos com emissão zero e por padrões crescentes de eficiência na utilização de combustíveis (McAlinden et al., 2000; NRC, 2001, 2005; NAS, 2004).

Por outro lado, tem se observado também uma mudança de atitude das grandes montadoras a respeito da questão da emissão e, em particular, em relação às novas tecnologias. $\mathrm{O}$ que antes poderia ser descrito como uma obediência relutante às novas normas regulatórias está se tornando um competitivo campo de batalha. E a rapidez com que os fabricantes de autoveículos poderão introduzir novas tecnologias, que atendam aos novos padrões regulatórios, é crescentemente

(29) Envolve também as grandes companhias de petróleo - "as maiores companhias de petróleo estão gastando centenas de milhões de dólares em pesquisas e desenvolvimento com o hidrogênio" (FT.com, 24 mar. 2000, p. 1, versão obtida pela internet) -, as empresas mais diretamente relacionadas com as tecnologias básicas a partir das quais se desenvolverão as células de combustível. Tem envolvido também alianças e acordos horizontais entre as próprias montadoras, entre estas últimas e empresas especializadas no desenvolvimento de células de combustível (como, por exemplo, a canadense Ballard) e mesmo entre as montadoras e as empresas petrolíferas (como, por exemplo, entre a Shell e a Daimler-Chrysler) (FT.com, 24 mar. 2000).

(30) De fato, como demonstram claramente os estudos do U.S. Department of Energy (2002) e, especialmente, o NAS (2004), o advento da tecnologia da célula de combustível, muito provavelmente, terá um impacto na economia que irá muito além da indústria automobilística ou mesmo dos meios de transporte, de uma maneira mais geral. Não é casual que o título geral do último estudo mencionado é: The Hydrogen Economy (...). 
vista como uma vantagem competitiva potencialmente estratégica (NRC, 2001, 2003; DOC, 2005, 2006).

O potencial de ganhos e perdas associados à introdução das novas tecnologias é muito amplo, particularmente no caso da tecnologia da célula de combustível. Esta circunstância tem mobilizado amplos e crescentes orçamentos e grande atenção por parte das montadoras e dos respectivos governos que temem ficar alijados da competição se não dominarem a nova (ou as novas) tecnologia(s) (Carvalho, 2003; OTP, 2003, 2003b). ${ }^{31}$

Ainda que também exista a possibilidade da nova tecnologia permitir a entrada de novos competidores na montagem final de veículos, as possibilidades maiores de ingresso provavelmente se darão nos estágios intermediários da cadeia produtiva. Até porque as principais montadoras estão demonstrando que estão procurando se preparar, adequadamente, para enfrentar os novos desafios que certamente virão (Carvalho, 2003; OTP, 2003a).

De qualquer forma, as possibilidades de mudanças na configuração competitiva da indústria automobilística internacional - ou mesmo da arquitetura do produto e/ou da indústria (ver novamente item 1.2) - serão maiores com o advento da nova tecnologia. Um detentor da tecnologia de células de combustível poderia, eventualmente, ingressar na produção de automóveis ou ainda adquirir, mesmo sem entrar na montagem final, um papel de destaque na indústria se tiver, por exemplo, uma vantagem competitiva importante na produção e no fornecimento das novas unidades propulsoras dos veículos (Carvalho, 2003).

Em suma, com a proximidade do advento de uma nova tecnologia que altere uma das características básicas do automóvel (a sua forma de propulsão), as possibilidades de mudanças no seu processo competitivo - ou mesmo na estrutura da indústria - podem se ampliar mesmo até antes que a nova tecnologia venha a ser efetivamente introduzida.

\section{Considerações finais}

Em dois importantes trabalhos da primeira metade dos anos 1980, Abernathy et al. (1983) e Abernathy e Clark (1985), foi originalmente proposta a interessante noção de de-maturity industrial "significando um incremento da diversidade da tecnologia de produtos realmente oferecida no mercado, assim como um aumento da visibilidade [importância] competitiva da tecnologia"

(31) Em 2001, os gastos conjuntos (de empresas e de governo) em programas de $\mathrm{P} \& \mathrm{D}$, relativos às tecnologias de células de combustível para uso estacionário e em veículos, foram de aproximadamente US\$ 400 milhões (Japão), US\$220 milhões (EUA), US\$ 170 milhões (Europa) e US\$ 120 milhões (Canadá) (OTP, 2003a). 
(Abernathy et al., 1983, p. 29). ${ }^{32}$ Ainda segundo Abernathy e Clark (1985), existiriam três tipos principais de mudanças no ambiente industrial que poderiam criar as condições para o referido processo de de-maturity: os primeiros tipos de mudanças seriam as novas oportunidades tecnológicas que ampliariam as possibilidades de performance para novas aplicações que os conceitos existentes de design poderiam não viabilizar ou, então, viabilizar apenas com grande dificuldade $;^{33}$ os segundos tipos de mudanças seriam as alterações das demandas dos consumidores provenientes seja de mudanças nos gostos seja de alterações nos preços de [bens] substitutos ou complementares; os terceiros tipos seriam as mudanças decorrentes de modificações de política econômica ou de normas regulatórias.

É óbvio que não se pretende fazer aqui uma discussão dessa ampla e relevante questão, que é, claramente, muito mais abrangente do que o escopo específico deste artigo. Com efeito, o objetivo aqui - restrito apenas ao âmbito da inovação tecnológica - é tão-somente demonstrar que, também desse ponto de vista, existem fortes indícios, como se procurou apontar, que parecem justificar a postulação de que estaria em curso uma de-maturity (rejuvenescimento) da indústria automobilística. Não seria inoportuno, entretanto, destacar ainda que, tanto do ponto de vista das alterações das demandas dos consumidores como das modificações das normas regulatórias (ver parágrafo anterior), o setor automobilístico vem passando também por importantes mudanças. ${ }^{34}$

Claramente, a busca cada vez mais intensa por novas e mais limpas formas de propulsão para os veículos automotores está, em grande parte, respondendo às mudanças regulatórias já introduzidas nos principais mercados - e pelas novas normas que certamente virão - em decorrência da crescente preocupação com a maior eficiência energética dos autoveículos, com o efeito estufa e com a poluição em geral. De outra parte, tem se verificado também uma ampliação bastante significativa da participação dos chamados veículos

(32) Entendendo uma indústria madura como uma "em que a inicial incerteza [tecnológica] foi substituída por uma estabilidade nos conceitos básicos (core), uma estabilidade que permite que as tecnologias de processo sejam incorporadas nos equipamentos de capital ou no pessoal de engenharia e compradas no mercado" (Abernathy et al., 1983, p. 24). Substitui-se, portanto, assim, a noção de maturidade industrial associada ao crescimento das vendas e/ou ao aparecimento da segmentação do mercado pela natureza [maturidade] da sua tecnologia.

(33) Embora não tenham sido originalmente consideradas pelos autores, poderiam se destacar também as importantes inovações de processo "baseadas em um radical redesign do sistema inteiro de produção" (Freeman; Soete, 1997, p. 148) - desenvolvidas pelas montadoras japonesas, lideradas pela Toyota -, como uma importante fonte de mudança do ambiente econômico e competitivo, pelo menos (mas, provavelmente, não só) no caso da indústria automobilística (Womack et al., 1990; Clark; Fujimoto, 1991; Fine et al., 1996; Sturgeon; Florida, 1999; Fujimoto, 1999).

(34) Sem esquecer também as importantes mudanças no âmbito dos processos produtivos, tanto na dimensão organizacional quanto na tecnológica. 
multipropósito (MPV) e dos utilitários esportivos (SUVs) nos mercados automobilísticos dos países desenvolvidos. Nos EUA, por exemplo, os light trucks já respondem por mais de $50 \%$ do mercado, desde o início da presente década (EIU, 2000; DOC, 2005, 2006). Assim sendo, não apenas do ponto de vista das inovações tecnológicas - objeto deste artigo - parecem existir razões para se discutir seriamente a idéia de um processo de rejuvenescimento da indústria automobilística.

Do ponto de vista das inovações tecnológicas - como procuramos demonstrar ao longo deste artigo - existem significativas indicações de que estaria mesmo havendo uma mudança de comportamento na indústria automobilística, nos últimos anos. Tais indicações parecem emergir tanto quando se analisa os gastos em $\mathrm{P} \& \mathrm{D}$ e o número de patentes obtidas pelo setor automobilístico ao longo do tempo, quanto quando se compara a evolução recente da intensidade da $\mathrm{P} \& \mathrm{D}$ deste setor com ao do setor manufatureiro em geral e com o setor aeroespacial, no caso norte-americano em particular. É claro que o esforço que se fez aqui é preliminar e precisa ser aperfeiçoado e aprofundado em vários aspectos. Mas tal esforço aponta um tema de pesquisa interessante - e que não se restringe apenas à indústria automobilística, em particular - e parece confirmar a hipótese de trabalho aqui proposta.

\section{Referências bibliográficas}

ABERNATHY, W. J. e UTTERBACK, J. (1978). "Patterns of Industrial Innovation". In: Technology Review., vol. 50, ${ }^{\circ}$ 7, jun-jul.

ABERNATHY, W. J. e CLARK, K. B. (1985). "Innovation: Mapping the Winds of Creative Destruction". In: Research Policy. North-Holland, vol. 14, p. 3-22.

ABERNATHY, W. J. et al. (1983). Industrial Renaissance: Producing a Competitive Future for America. New York, Basic Books.

CALABRESE, G. (2001). "R\&D Globalization in the Car Industry". CoCKEAS.

CARVALHO, E. G. de (2002). "A Comparative Study on Product and R\&D Strategies of Majors Assemblers of Brazilian Car Industry". Décimo GERPISA International Colloquium, Paris.

(2003).“Globalização e Estratégias Competitivas na Indústria Automobilística: uma Abordagem a Partir das Principais Montadoras Instaladas no Brasil”. Campinas, IE/UNICAMP. (Tese de Doutoramento, mimeo).

(2005a). "Globalização e Estratégias Competitivas na Indústria Automobilística: uma Abordagem a Partir das Principais Montadoras Instaladas no Brasil". In: Gestão \& Produção. Vol. 12, nº 1, p. 121-133, jan-abr. 2005.

(2005b). "Uma Contribuição para o Debate sobre a Globalização da Indústria Automobilística Internacional”. In: Economia e Sociedade. Vol. 14, nº 2, p. 287-317, juldez. 2005. 
Enéas Gonçalves de Carvalho

CHANARON, J. J. (2001). "Implementing Technological and organizational Innovations and management of Core Competences: Lessons from the automotive Industry". CoCKEAS.

CLARK, K. B. e FUJIMOTO, T. (1991). Product Development, Performance Strategy, Organization and Management in the World Auto Industry. Cambridge, Harvard Business Press.

CORIAT, B. e WEINSTEIN, O. (2001). "The Organization of R\&D and the Dynamics of Innovation: a 'Sectorial' View'. Paris, Working Paper Essay.

DERTOUZOS, M. L. et al. (1989). Made in America: regaining the Productive Edge. Cambridge, MIT Press.

DOC - U.S. DEPARTMENT OF COMMERCE (2005). "The Road Ahead for the U.S. Auto Industry". Washington.

(2006). "The Road Ahead for the U.S. Auto Industry". Washington.

DOE - U.S. DEPARTMENT OF ENERGY (2000). "Technology Roadmap for the $21^{\text {st }}$ Century truck Program". Washington. (2002). "National hydrogen Energy Roadmap". Washington.

DOSI, G. et al., (1998). Technical changy and Economic Theory. London, Pinter.

EIU (2000). Global niche vehicle markets: prospects to 2005. In: EIU Motor Business Japan. In: EIU Motor Business International. Cap. 9, 2000.

FINE, C. H. et al. (1996). The U.S. Automobile Manufacturing Industry. U.S. Department of Commerce, Office of Technology Policy.

FINANCIAL TIMES, vários números.

FREEMAN, C. e SOETE, L. (1997). The Economics of Industrial Innovation. Mit Press, Cambridge.

FREYSSENET, M. et al. (1998). One Best Way? Trajectories and Industrial Models of the World's Automobile Producers. Oxford, Oxford University Press.

FUJIMOTO, T. (1999). The Evolution of a Manufacturing System at Toyota. New York, Oxford University Press.

FUJIMOTO, T. e TAKEISHI, A. (2001). "Automobiles: Strategy-Based Lean production System". Tokyo, the University of Tokyo, Discussion Papers.

HELPER, S. e KHAMBETE, S. (2005). Off-shoring, interface and collaboration across the supply Chain: a case study in automotive product development. Case Western Reserve University.

IANSITI, M. e CLARK, K. B. (1994). "Integration and dynamic capability: evidence from product development in automobiles and mainframe computers". In: Industrial and Corporate Change, vol. $3, \mathrm{n}^{\circ} 3$, p. 557-605.

JONES, D. T. (1985) "Vehicles" In: FREEMAN, C. (ed.) Engineering and Vehicles: technological trends and employment. Aldershot, Gower Publishing Company LTDA. 
LYNCH, T. M. et al. (2000). Industrial Performance Center Conference Summary on Globalization. Cambridge: Massachusetts Institute of Technology, 2000. 21 p. Working paper.

MALERBA, F. (2001). "Sectorial Systems of Innovation and Production". University of Milan, Working Paper Essy.

MARSILI, O. (2001). The Anatomy and Evolution of Industries. Edward Elgar, Cheltenham.

McALINDEN, S. P. et al. (2000). "Michigan Automotive Partnership Research Memoradum n ${ }^{\circ}$ 2". Michigan, UMTRI Report n 2000-24-2.

MILLER, R. (1994). "Global R\&D Networks and Large-Scale Innovations: the Case of The Automobile Industry". In: Research Policy. North-Holland, vol. 23, p. 27-46.

NATIONAL ACADEMY OF SCIENCES. "The Hydrogen Economy: Opportunities, Costs, Barriers, and R\&D Needs". Washington.

NRC (1998). NATIONAL RESEARCH COUNCIL. "Review of Research and Development Plan for the Office of Advanced Automotive Technologies". Washington.

(2000). NATIONAL RESEARCH COUNCIL. "Review of Research Program of the Partnership for a New Generation of Vehicles. Sixth Report". Washington.

(2001). NATIONAL RESEARCH COUNCIL. "Review of Research Program of the Partnership for a New Generation of Vehicles. Seventh Report". Washington.

Washington.

(2003). NATIONAL RESEARCH COUNCIL. "Personal Cars and China".

NRC (2005). NATIONAL RESEARCH COUNCIL. "Review of Research Program of the FreedomCAR and Fuel Partnership: First Report". Washington.

(1999). NATIONAL SCIENCE FOUNDATION. "U. S. Corporate R\&D: Volume I. Top 500 Firms in R\&D by Industry Category". Arlington.

NSF (2004). NATIONAL SCIENCE FOUNDATION. "Science \& engineering indicators". Arlington.

(2006). NATIONAL SCIENCE FOUNDATION. "Science \& engineering indicators". Arlington.

NELSON, R. R. e WINTER, S. G. (1982). An Evolutionary Theory of Economical Change. Cambridge, Harvard University Press.

OECD (2004). Can Cars Come Clean? Strategies For Low-Emission Vehicles. Paris.

OTP (1998). "The New Innovators: Global Patenting Trends in Five Sectors. Washington. (2003a). "Fuel Cell Vehicles: Race a New Automotive Future". Washington.

(2003b). "The U.S. Competitive Position in Advanced Automotive Technologies". Washington.

PAVITT, K. (1984). "Patterns of technical change: towards a taxonomy and theory". In: Research Policy. North-Holland, vol. 13, n 6, p. 343-373.

RAPP, W. V. (2000). "Automobiles: Toyota Motor Corporation: Gaining and Sustaining Long-term Advantage Through Information Technology". Columbia University, mimeo. 
Enéas Gonçalves de Carvalho

ROSENBERG, N. (1994). Exploring the Black Box: Technology, Economics and History. Cambridge, Cambridge University Press.

STURGEON, T. e FLORIDA, R. (1999). "The World that Change the Machine: Globalization and Jobs in the Automotive Industry". Final Report, IMVP.

TEECE, D. J. et al. (1997). "Dynamic Capabilities and Strategic Management". In: Strategic Management Journal, vol. 18, $\mathrm{n}^{\mathrm{o}}$ 7, p. 509-533.

U.S. INDUSTRY \& TRADE OUTLOOK (2000). “Automotive Parts”. Cap. 37, p. 1-14. McGraw Hill, New York.

UTTERBACK, J. M. (1996). Dominando a Dinâmica da Inovação. Qualitymark Ed., Rio de Janeiro

VICKERY, G. (1996). "Globalization in the Automobile Industry". In: OECD (ed.). Globalization of Industry. Paris.

WATANABE, S. (1987). Microeletronics, Automation and Employment in the Automobile Industry. John Wiley \& Sons, New York.

WOMACK, J. P et al. (1990). The Machine that Change the World. Macmillan, New York. 


\section{Anexo estatístico}

\section{Gráfico 1A}

Intensidade de $\mathrm{P} \& \mathrm{D}$ (gastos de $\mathrm{P} \& \mathrm{D} /$ Produção) na indústria automotiva nos países membros da OECD.

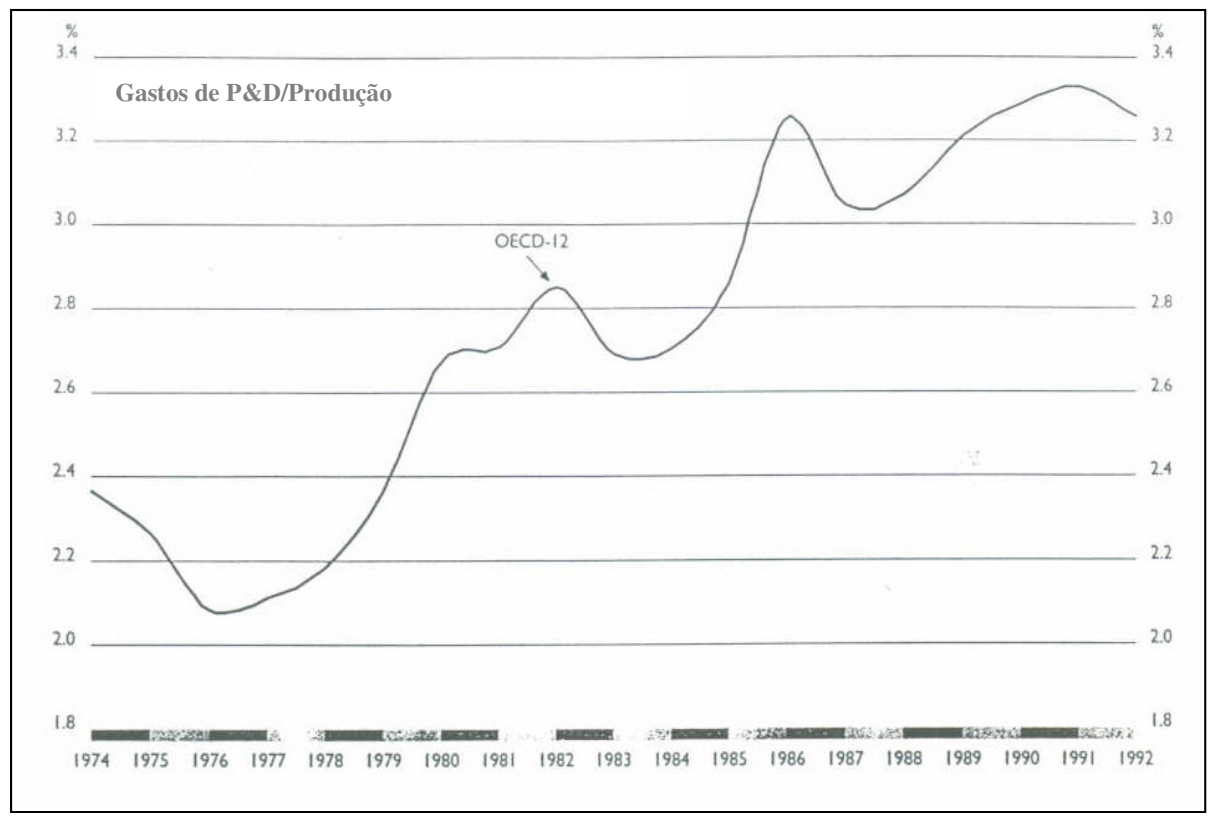

Nota: OECD - 12 corresponde aos países: Austrália, Canadá, Finlândia, França, Alemanha, Itália, Japão, Países Baixos, Espanha, Suécia, Reino Unido, Estados Unidos.

Fonte: Vickery (1996).

Tabela 1A

Posição das montadoras no ranking geral do número de patentes nas mais importantes tecnologias automotivas avançadas no período entre 1983 e 2001

\begin{tabular}{|c|c|c|c|c|c|c|c|}
\hline \multirow{2}{*}{$\begin{array}{c}\text { Empresas } \\
\text { Automobilísticas }\end{array}$} & \multicolumn{7}{|c|}{ Ranking do Número de Patentes nas Principais Tecnologias Avançadas } \\
\hline & $\mathrm{CCA}^{1}$ & $\mathrm{NRC}^{2}$ & $\mathrm{VHE}^{3}$ & $\mathrm{CIDI}^{4}$ & $\mathrm{CE}^{5}$ & $\mathrm{ML}^{6}$ & $\operatorname{MCI}(\mathrm{H} . \mathrm{ICE})^{7}$ \\
\hline General Motors & 3 & 4 & 6 & 5 & 7 & 34 & 10 \\
\hline Toyota & 6 & 1 & 2 & 2 & 1 & 4 & - \\
\hline Daimler-Chrysler & 9 & 7 & 5 & 3 & 5 & 18 & - \\
\hline Honda & 13 & 10 & 1 & - & - & 7 & - \\
\hline Ford & - & 2 & 3 & 9 & 2 & - & - \\
\hline Volkswagen & - & 28 & 20 & - & 13 & 22 & - \\
\hline Fiat & - & - & - & 7 & 29 & - & - \\
\hline \multicolumn{8}{|c|}{$\begin{array}{l}\text { Nota: }{ }^{1} \text { Célula de Combustível Automotivo; }{ }^{2} \text { Novos Regimes de Combustão; }{ }^{3} \text { Veículos Híbridos } \\
\text { Elétricos; }{ }^{4} \text { Combustão com Injeção Direta; } ;{ }^{5} \text { Controle de Emissão; } ;{ }^{6} \text { Materiais Leves; }{ }^{7} \text { Motores de }\end{array}$} \\
\hline
\end{tabular}


Tabela 2A

Fluxo de Patentes Registradas no USPTO pelas montadoras selecionadas (U.S. Patent Trademark Office) (1990 a 2005)

\begin{tabular}{|c|c|c|c|c|c|c|c|c|c|c|c|c|c|c|c|c|c|c|}
\hline Empresas & $\begin{array}{c}\text { Até } \\
1989\end{array}$ & 1990 & 1991 & 1992 & 1993 & 1994 & 1995 & 1996 & 1997 & 1998 & 1999 & 2000 & 2001 & 2002 & 2003 & 2004 & 2005 & Acumulado \\
\hline Ford & 2447 & 265 & 254 & 285 & 332 & 373 & 358 & 394 & 366 & 494 & 435 & 380 & 410 & 423 & 412 & 435 & 351 & 8414 \\
\hline GM & 4785 & 388 & 449 & 413 & 445 & 336 & 285 & 208 & 278 & 304 & 278 & 257 & 183 & 488 & 293 & 381 & 396 & 10167 \\
\hline Chrysler & 535 & 120 & 91 & 54 & 47 & 131 & 133 & 192 & 147 & 191 & 249 & 175 & 45 & 14 & 11 & 4 & 5 & 2144 \\
\hline Total EUA & 7767 & 773 & 794 & 752 & 824 & 840 & 776 & 794 & 791 & 989 & 962 & 812 & 638 & 925 & 716 & 820 & 752 & 20725 \\
\hline Honda & 2683 & 430 & 271 & 224 & 285 & 271 & 270 & 334 & 378 & 448 & 536 & 539 & 661 & 773 & 769 & 868 & 823 & 10563 \\
\hline Nissan & 3645 & 383 & 348 & 361 & 231 & 155 & 128 & 116 & 150 & 178 & 233 & 270 & 293 & 273 & 274 & 277 & 300 & 7615 \\
\hline Toyota & 4062 & 218 & 221 & 223 & 200 & 177 & 217 & 192 & 263 & 454 & 490 & 419 & 401 & 372 & 478 & 484 & 425 & 9296 \\
\hline Total Japão & 10390 & 1031 & 840 & 808 & 716 & 603 & 615 & 642 & 791 & 1080 & 1259 & 1228 & 1355 & 1418 & 1521 & 1629 & 1548 & 27474 \\
\hline Hyundai & 6 & 2 & 18 & 22 & 32 & 72 & 117 & 229 & 258 & 325 & 360 & 388 & 675 & 589 & 315 & 230 & 177 & 3815 \\
\hline Total Ásia & 10396 & 1033 & 858 & 830 & 748 & 675 & 732 & 871 & 1049 & 1405 & 1619 & 1616 & 2030 & 2007 & 1836 & 1859 & 1725 & 31289 \\
\hline Daimler $^{1}$ & 1172 & 133 & 118 & 113 & 129 & 105 & 118 & 185 & 211 & 580 & 407 & 636 & 769 & 548 & 381 & 400 & 223 & 6228 \\
\hline Renault & 450 & 13 & 10 & 8 & 5 & 5 & 10 & 4 & 5 & 1 & 6 & 12 & 15 & 18 & 13 & 15 & 21 & 611 \\
\hline Peugeot & 325 & 16 & 10 & 16 & 7 & 4 & 1 & 2 & 8 & 5 & 8 & 7 & 7 & 9 & 7 & 15 & 16 & 463 \\
\hline Fiat & 400 & 29 & 36 & 27 & 14 & 20 & 16 & & 14 & 8 & 11 & 11 & 3 & 4 & 10 & 4 & 2 & 609 \\
\hline Volkswagen & 40 & 13 & 8 & 20 & 21 & 20 & 12 & 8 & 10 & 17 & 41 & 71 & 56 & 40 & 49 & 40 & 41 & 507 \\
\hline Total Europa & 2387 & 204 & 182 & 184 & 176 & 154 & 157 & 199 & 248 & 611 & 473 & 737 & 850 & 619 & 460 & 474 & 303 & 8418 \\
\hline Total Geral & 20550 & 2010 & 1834 & 1766 & 1748 & 1669 & 1665 & 1864 & 2088 & 3005 & 3054 & 3165 & 3518 & 3551 & 3012 & 3153 & 2780 & 60432 \\
\hline
\end{tabular}

Fonte: Elaborado pelo autor a partir de informações do USPTO. 
Quadro 1A

Áreas tecnológicas de maior interesse na Indústria Automobilística

\begin{tabular}{|c|c|}
\hline Áreas Tecnológicas & Tecnologias Candidatas \\
\hline Materiais avançados leves & $\begin{array}{l}\text { Tecnologias combinadas e Adesivas; Fibra de vidro e resina de fibras compostas; Cerâmicas; } \\
\text { Plásticos moldáveis; Alumínio, Titânio, Magnésio; Aço de alta resistência. }\end{array}$ \\
\hline Conversão de energia & $\begin{array}{l}\text { Motor de injeção direta quatro tempos; Turbinas a gás; Células de Combustível; Veículos elétricos } \\
\text { ou híbridos; Diesel avançado. }\end{array}$ \\
\hline Dispositivos de armazenagem de energia & Ultracapacitores; Baterias avançadas ( $\mathrm{p} /$ Veículos elétricos ou híbridos); Alternadores. \\
\hline Sistemas elétricos eficientes & $\begin{array}{l}\text { Power eletronics; Motores elétricos avançados; Controladores elétricos eficientes (para frenagem } \\
\text { regenerativa, power management e distribuição de sinal). }\end{array}$ \\
\hline Recuperação de energia gasta & Sistemas termoelétricos. \\
\hline Métodos avançados de análise e projeto & Mecânica estrutural; Prototipagem virtual; Simulações; Fluidodinâmica. \\
\hline Redução de perdas mecânicas & Tribologia; Lubrificantes. \\
\hline Aerodinâmica/Melhoria na Resistência de rolagem & Ferramentas de Simulação; Novos Materiais. \\
\hline Manufatura avançada & $\begin{array}{l}\text { Supercomputadores; Manufatura ágil (máquinas e ferramentas programáveis, quase net-shape } \\
\text { casting); Comunicação de dados em alta velocidade e administração de dados; Prototipagem rápida } \\
\text { (manufatura virtual e técnicas complexas de visualização); Técnicas avançadas de } \\
\text { forjamento/junção. }\end{array}$ \\
\hline $\begin{array}{l}\text { Melhoria da eficiência de motores de combustão } \\
\text { interna (Gestão da combustão) }\end{array}$ & $\begin{array}{l}\text { Abastecimento estratificado/motor de combustão enxuta; Injeção direta; Controle transitório de } \\
\text { combustível/injeção de combustível. }\end{array}$ \\
\hline Controles de emissão & $\begin{array}{l}\text { Avançados catalisadores de exaustão de óxido nitroso; Diagnóstico a bordo (sistemas de } \\
\text { evaporação, diagnose de catalisadores, falha de injeção de motores); Avançadas particulate trap. }\end{array}$ \\
\hline $\begin{array}{l}\text { Avançada Crashworthiness/Tecnologia de proteção } \\
\text { dos ocupantes }\end{array}$ & $\begin{array}{l}\text { Projeto estrutural e materiais avançados leves; Simulação por computador de colisão de veículos; } \\
\text { Sistemas avançados de controle de ocupantes incluindo sensores. }\end{array}$ \\
\hline
\end{tabular}


Gráfico $2 \mathrm{~A}$

Patentes da indústria automotiva de 1969 a 1986

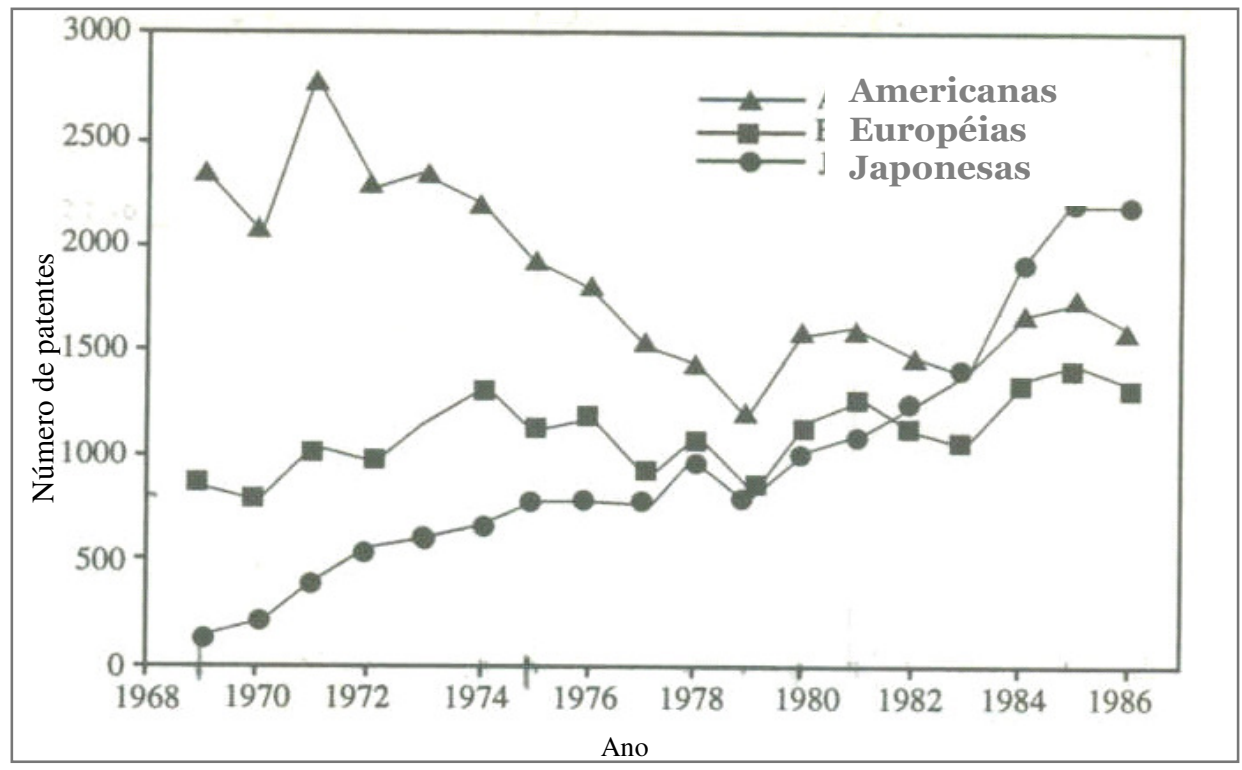

Notas: As cifras referem-se às patentes obtidas no USPTO pelas firmas (montadoras e fabricantes de autopeças) da indústria automobilística e agrupadas pela região da matriz. Assim, os gastos da General Motors no mundo inteiro estão consolidados como "norte-americanos" e os da Volkswagen, como "europeus".

Fonte: Freeman e Soete (1997).

Tabela 3A

Intensidade de $\mathrm{P} \& \mathrm{D}$ industrial ( $\mathrm{P} \& \mathrm{D} /$ vendas líquidas) das empresas norte-americanas (exceto fundos federais), por setor ${ }^{1}$ (1986-1996)

\begin{tabular}{|c|c|c|c|c|c|c|c|c|c|c|c|}
\hline \multirow{2}{*}{$\begin{array}{l}\text { Indústrias de } \\
\text { Manufatura }\end{array}$} & \multicolumn{11}{|c|}{ Porcentagem (\%) } \\
\hline & 1986 & 1987 & 1988 & 1989 & 1990 & 1991 & 1992 & 1993 & 1994 & 1995 & 1996 \\
\hline $\begin{array}{l}\text { Computadores e } \\
\text { Máquinas de Calcular } \\
\text { (357) }\end{array}$ & 12,4 & 12,3 & 11,2 & 13,1 & 14,4 & 14,9 & 13,7 & 9,8 & 7,9 & 8,1 & 9,9 \\
\hline $\begin{array}{l}\text { Outras Máquinas } \\
\text { (exceto elétricos) (351- } \\
56 ; 58-59)\end{array}$ & 2,9 & 3,0 & 2,8 & 2,6 & 2,3 & 2,9 & 2,9 & 2,5 & 2,5 & 2,4 & 2,9 \\
\hline $\begin{array}{l}\text { Equipamentos de } \\
\text { Comunicação (366) }\end{array}$ & 5,2 & 5,5 & 6,1 & 6,8 & 6,1 & ND. & 7,0 & 10,1 & 10,3 & 8,0 & 8,5 \\
\hline $\begin{array}{l}\text { Componentes } \\
\text { Eletrônicos (367) }\end{array}$ & 9,2 & 8,5 & 8,0 & 7,7 & 7,4 & 7,2 & 7,0 & 7,8 & 7,3 & 8,0 & 8,5 \\
\hline Automobilística (371) & 3,3 & 3,4 & 3,4 & 3,7 & 3,7 & 4,1 & 4,0 & 3,7 & 3,4 & 3,6 & 4,2 \\
\hline Aeroespacial $(372 ; 376)$ & 4,0 & 3,6 & 3,9 & 3,3 & 3,1 & 4,0 & 4,7 & 4,7 & 5,3 & 4,2 & 4,5 \\
\hline $\begin{array}{l}\text { Instrumentos Científicos } \\
\text { e Mecânicos (381-382) }\end{array}$ & 8,4 & 8,1 & 7,6 & 6,9 & 6,9 & 6,3 & 6,2 & 6,4 & 5,8 & 6,6 & 6,7 \\
\hline Medicamentos (283) & 8,4 & 8,7 & 8,8 & 8,9 & 8,8 & 8,9 & 9,6 & 12,5 & 10,2 & 10,4 & 10,1 \\
\hline Total Manufatura & 3,2 & 3,1 & 3,1 & 3,1 & 3,1 & 3,2 & 3,3 & 3,1 & 2,9 & 2,9 & 3,3 \\
\hline
\end{tabular}


Inovação tecnológica na indústria automobilística: características e evolução recente

Tabela 4A

Intensidade de $\mathrm{P} \& \mathrm{D}$ industrial (P\&D/vendas líquidas) das empresas norte-americanas (exceto fundos federais), por setor ${ }^{1}(1997-2001)$

\begin{tabular}{l|c|c|c|c|c}
\hline \multirow{2}{*}{\multicolumn{1}{c}{ Indústrias de Manufatura }} & \multicolumn{5}{c}{ Porcentagem (\%) } \\
\cline { 2 - 5 } & 1997 & 1998 & 1999 & 2000 & 2001 \\
\hline Farmacêuticos (3254) & 11,8 & 11,1 & 10,5 & 9,8 & 7,8 \\
\hline $\begin{array}{l}\text { Computadores e Equipamentos Periféricos } \\
\text { (3341) }\end{array}$ & 7,7 & 7,2 & 6,4 & 6,5 & 7,6 \\
\hline Equipamentos de Comunicação (3342) & 6,9 & 9,9 & 11,6 & 9,6 & 16,6 \\
\hline Semicondutores e outros Equipamentos & 9,1 & 8,6 & 8,3 & 7,4 & 10,5 \\
\hline Eletrônicos (3344) & 3,7 & 2,2 & 2,9 & 3,2 & 3,5 \\
\hline Automobilística (3361-3363) & 3,3 & 2,9 & 3,2 & 2,8 & 3,0 \\
\hline Aeroespaciais (3364) & 8,3 & 9,4 & 7,7 & 13,1 & 9,0 \\
\hline Equipamentos Médicos (3391) & ND & ND & 3,2 & 3,3 & 3,6 \\
\hline Total Manufatura & & & & \\
\hline
\end{tabular}

Nota: ${ }^{1}$ Código NAICS.

Fonte: Adaptado pelo autor a partir de vários números de NSF (National Patterns of Research and Development). 